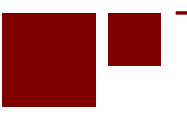

C E N T E R for RETIREMENT RES E A R C H at BOSTON COLLEGE

\title{
THE MORTALITY EFFECTS OF RETIREMENT: EVIDENCE FROM SOCIAL SECURITY ELIGIBILITY AT AGE 62
}

\author{
Maria D. Fitzpatrick and Timothy J. Moore
}

CRR WP 2016-7

August 2016

\author{
Center for Retirement Research at Boston College \\ Hovey House \\ 140 Commonwealth Ave \\ Chestnut Hill, MA 02467 \\ Tel: 617-552-1762 Fax: 617-552-0191 \\ http://crr.bc.edu
}

Maria D. Fitzpatrick is an assistant professor of policy and management at Cornell University. Timothy J. Moore is an assistant professor of economics at George Washington University. The research reported herein was performed pursuant to a grant from the U.S. Social Security Administration (SSA) funded as part of the Retirement Research Consortium. The opinions and conclusions expressed are solely those of the authors and do not represent the opinions or policy of SSA, any agency of the federal government, Cornell University, the George Washington University, or Boston College. Neither the United States Government nor any agency thereof, nor any of their employees, makes any warranty, express or implied, or assumes any legal liability or responsibility for the accuracy, completeness, or usefulness of the contents of this report. Reference herein to any specific commercial product, process or service by trade name, trademark, manufacturer, or otherwise does not necessarily constitute or imply endorsement, recommendation or favoring by the United States Government or any agency thereof.

(C) 2016, Maria D. Fitzpatrick and Timothy J. Moore. All rights reserved. Short sections of text, not to exceed two paragraphs, may be quoted without explicit permission provided that full credit, including $(\mathbb{C}$ notice, is given to the source. 


\section{About the Steven H. Sandell Grant Program}

This paper received funding from the Steven H. Sandell Grant Program for Junior Scholars in Retirement Research. Established in 1999, the Sandell program's purpose is to promote research on retirement issues by scholars in a wide variety of disciplines, including actuarial science, demography, economics, finance, gerontology, political science, psychology, public administration, public policy, sociology, social work, and statistics. The program is funded through a grant from the Social Security Administration (SSA). For more information on the Sandell program, please visit our website at: http://crr.bc.edu/?p=9570, send e-mail to crr@bc.edu, or call (617) 5521762.

\section{About the Center for Retirement Research}

The Center for Retirement Research at Boston College, part of a consortium that includes parallel centers at the University of Michigan and the National Bureau of Economic Research, was established in 1998 through a grant from the Social Security Administration. The Center's mission is to produce first-class research and forge a strong link between the academic community and decision-makers in the public and private sectors around an issue of critical importance to the nation's future. To achieve this mission, the Center sponsors a wide variety of research projects, transmits new findings to a broad audience, trains new scholars, and broadens access to valuable data sources.

Center for Retirement Research at Boston College

Hovey House

140 Commonwealth Ave

Chestnut Hill, MA 02467

Tel: 617-552-1762 Fax: 617-552-0191

http://crr.bc.edu

Affiliated Institutions:

The Brookings Institution

Syracuse University

Urban Institute 


\section{Key Findings and Policy Implications}

This paper examines the link between retirement and health by examining whether mortality changes discontinuously at the Social Security eligibility threshold at age 62. It uses data from the National Center for Health Statistics’ Multiple Cause of Death, the Health and Retirement Study, and the Social Security Master Beneficiary Records and Numident Files. Critical components of the analysis include the regression discontinuity framework and the use of detailed objective health outcomes. Key limitations of our estimates are of the effects on mortality net of any anticipatory changes in health investments, the difficulty in knowing whether the results extend to retirement at ages other than 62, and a lack of available data on other objective health outcomes.

The paper found that:

- Many individuals decide to claim Social Security as soon as they can after turning age 62.

- There is a coincident increase in mortality soon after turning 62.

- The mortality increase is robust for males but not for females.

- The increase in mortality seems to be more connected to stopping work than to claiming Social Security itself.

The policy implications of the findings are:

- There may be an increase in mortality risks when people stop work.

- More research may shed light on the reasons for this and the ways these elevated risks could be reduced.

- Initiatives and policies that assist people through the transition to retirement may have health benefits. 


\begin{abstract}
Social Security eligibility begins at age 62, and approximately one third of Americans immediately claim benefits upon reaching that age. We study the link between retirement and health by examining whether mortality changes discontinuously at this threshold. Using mortality data that covers the entire U.S. population and includes exact dates of birth and death, we document a robust two percent increase in overall male mortality immediately after age 62. The rise in mortality is closely connected to changes in labor force participation, implying that mortality increases by approximately 20 percent among those who stop working because Social Security is available.
\end{abstract}




\section{Introduction}

There is enormous interest in the effect of retirement on health, especially given the aging of the population and reforms to retirement policies underway in the United States and other developed countries. However, the interdependence between health outcomes and retirement status, which commonly leads individuals in poorer health to retire earlier, means that it is difficult to disentangle this relationship. A large literature attempts to identify this relationship using public policies and firm-specific rules that affect retirement as exogenous sources of variation. Some researchers use longstanding pension rules in the U.S. and Europe that affect the likelihood of retirement (e.g., Charles, 2004; Bound and Waidmann, 2007; Neuman, 2008; Coe and Zamarro, 2011), while others use the introduction of early retirement incentives (e.g., Coe and Lindeboom, 2008; Hernaes et al., 2013) or changes to labor market policies (e.g., Kuhn, Wuellrich and Zweimüller, 2010). Despite the wide range of settings and variety of empirical strategies, these studies have failed to produce clear and consistent findings as to how retirement affects health.

We contribute to this literature by examining how mortality changes in the U.S. at age 62, when most individuals become eligible for Social Security Retirement and Survivors Insurance (“Social Security”). Many choose to claim Social Security immediately upon reaching 62. Figure 1 shows the fraction of males and females ever having claimed Social Security, constructed by age (in months) using a one percent extract of Social Security administrative data for 1921-1948 birth cohorts born. ${ }^{1}$ The rise in new claims at age 62 is striking: 31 percent first claim upon turning 62, with males and females claim at similar rates. This leads to other discontinuous changes; as we show below, approximately one-tenth of males retire in the month they turn 62 .

We show that there is a discontinuous change in the age-mortality relationship at age 62 . We identify this using a regression discontinuity (RD) design and restricted-use versions of the National Center for Health Statistics’ Multiple Cause of Death (MCOD) data. MCOD data are compiled from death certificates and include exact dates of birth and death. We show that aggregate mortality increases by 1.5 percent in the month individuals turn 62 . This is driven by a two percent increase in male mortality that is statistically significant, robust to a wide variety of specification choices, and substantially greater than at nearby ages with known policy discontinuities (e.g., ages 60 and 65). We estimate a one percent increase in mortality for females in the month they turn 62; however; it is neither robust nor larger than mortality estimates at nearby ages.

\footnotetext{
${ }^{1}$ All types of Social Security claims are included in this figure. We explain more about these data in the next section.
} 
Our approach follows other studies using age-based eligibility thresholds to understand the impact of policies and economic outcomes (e.g., Card, Dobkin and Maestas, 2008, 2009; Anderson, Dobkin and Gross, 2012, 2014). ${ }^{1}$ Similar to those papers, we are estimating the effect of a known policy threshold and can only attribute effects to that policy if there are no other relevant policy discontinuities at the same age. ${ }^{2}$ To our knowledge, no major federal or pension policies change discontinuously at age $62 .{ }^{3}$ While state-level policies may have specific rules at age 62, we show our estimates do not depend on particular states or regions.

There is substantial heterogeneity in the mortality increase at age 62, which we use to show that the increase in mortality appears to be related to reduced labor force participation. Using data from the Health and Retirement Study (HRS), we show that the groups with the largest increases in mortality when they turn 62, such as unmarried males or males not completing high school, have the largest decreases in labor force participation at that age. This pattern is not present for Social Security receipt itself, or for changes in health insurance status or household income at age 62. We also find that the causes of death with the largest increases at age 62 are consistent with previous findings on the health effects of job loss (e.g. Eliason and Storrie, 2009a; Kuhn, Wuellrich, and Zweimüller, 2010; Browning and Heinesen, 2012) and evidence of how health behaviors change at retirement (Ayyagari, 2016).

If we attribute higher male mortality at age 62 to retirement from the labor force, our results suggest that the mortality risks of males who retire upon reaching 62 are elevated by approximately 20 percent once Social Security is available. If these effects persist through to the current Full Retirement Age (FRA) of 66, their life expectancy could decrease by three months as a result. We cannot rule out a similar relationship between retirement and mortality risks for females, because their labor force participation only slightly decreases in the month they turn 62 . We make important contributions to understanding the relationship between retirement and health. While a negative correlation between retirement and health has been documented in

\footnotetext{
${ }^{1}$ Others have considered Social Security eligibility at 62 as an age-based threshold. Ayyagari (2016) uses it to examine the link between retirement and smoking. Angrist and Pischke (2014) open their RD chapter with three examples, including: “The Social Security Administration won’t pay you a penny in retirement benefits until you've reached age 62” (p.147).

${ }^{2}$ We deal with the potential role of anticipation in our robustness tests, showing that the results for males remain similar once we remove the influence of deaths just before and after they turn 62 .

${ }^{3}$ The Federal Employees Retirement System (FERS), which provides benefits to civilian federal employees, has a minimum claiming age of 62 for employees with five or less years of service and a change in incentives at age 62 . The impact on national retirement should be relatively small; in 2011, there were 27,006 "normal retirees" with an average of 20.9 years of service (see https://www.opm.gov/policy-data-oversight/data-analysis-documentation/federal-employment-reports/reports-publications/retirement-age-trend-analysis.pdf).
} 
many settings, our paper is one of the first to use U.S. administrative data to examine how an objective measure of health responds to a widespread change in retirement incentives. Within the large literature on how retirement affects health, the most consistent relationship is that subjective health and wellbeing measures are improved by retirement. However, many of these same studies find no effect of retirement on objective health outcomes (e.g., Neuman, 2008; Coe and Zamarro, 2011), perhaps because self-reported health outcomes are subject both to response errors and justification biases related to the transition to retirement (Bound, 1991; Baker, Stabile and Deri, 2004). Our study therefore establishes a clearer causal link between retirement and an objective health outcome than most of the previous literature. ${ }^{4}$

Our paper complements recent studies using European administrative data, which find mixed results as to how retirement affects mortality. ${ }^{5}$ Bloeman, Hochguertel and Zweerink (2013) find that early retirement among public sector workers in the Netherlands decreased mortality, while Hallberg, Johansson, Josephson (2015) find a similar result for Swedish military officers induced to retire early. Hernaes et al. (2013) find no mortality effects resulting from an early retirement scheme in Norway. Kuhn, Wuellrich and Zweimüller (2010) examine the effects of unemployment insurance extensions that enabled older blue collar workers in Austria to retire early, finding it led to higher mortality among males. In addition to institutional differences, the broad impact of Social Security eligibility in the U.S. allows us to generate more precise estimates than most of these studies and better explore the mechanisms underpinning our findings.

Our estimates apply to individuals immediately claiming at age 62, who differ from later claimants in terms of their socioeconomic and health characteristics (Gustman and Steinmeier,

\footnotetext{
${ }^{4}$ Some of the more prominent studies include Charles (2004), who uses HRS data and age discontinuities in the financial incentives to retire to find that retirement increases subjective wellbeing. Coe and Lindeboom (2008) also use the HRS, focusing on workers subject to "early retirement windows." They find no detrimental effects on physical health and a temporary increase in self-reported wellbeing. Other studies using the HRS include Neuman (2008), who finds subjective wellbeing improves with retirement and no change in more objective outcomes; Dave, Rashad and Spasojevic (2009), who rely on individual fixed effects to conclude that retirement has negative effects on mental and physical health; and Insler (2014), who uses retirement expectations as instruments and finds that some ailments decrease with retirement. Studies using European studies include Bound and Waidmann (2007), who examine the effect of retirement on subjective and objective measures of health using the English Longitudinal Survey on Aging (ELSA) and rules governing public pension eligibility. They find no effects, except some results that suggest that males experience a small and temporary improvement in physical health. Behncke (2012), using pension rules, matching methods and similar ELSA data, finds that retirement increases the probability of being diagnosed with a chronic condition. Coe and Zamarro (2011) use cross-country data from the Survey of Health Aging and Retirement in Europe (SHARE) and variation in retirement rules; they estimate a small positive effect of retirement on self-reported health. In reviewing these and other studies, Eibich (2014) notes that "existing empirical evidence is inconclusive" and that "the mechanisms behind these effects remain unclear" (p. 1).

${ }^{5}$ A related study by Snyder and Evans (2006) examines how income affects mortality. Using the Social Security "notch," they find a decrease in Social Security income decreases mortality. They argue that an increase in part-time work is the reason that mortality decreases, which is consistent with our findings.
} 
2005; Li, Hurd and Loughran, 2008). However, they represent approximately one third of the U.S. population and a higher fraction of Social-Security-covered workers. It is also the group most directly affected by any changes to the Early Eligibility Age (EEA) of 62. Unlike the Full Retirement Age (FRA), it has not been modified to increase seniors' labor force participation and improve the fiscal outlook of Social Security. Our findings suggest changes to the EEA or other policies that increase work among age-62 claimants may increase life expectancy, which is important for assessing the welfare implications of changing Social Security rules.

There is typically a strong correlation between mortality and other objective health measures (Idler and Benyamini, 1997). This suggests that our results likely reflect a more general decline in physical health upon retirement, at least among age-62 Social Security claimants, although further research would be required to establish whether this is indeed the case.

The rest of the paper is organized as follows. In Section 2, we provide background about Social Security and claiming at age 62. In Section 3, we describe the data and sample. In Section 4 , we analyze the change in mortality upon reaching age 62. In Section 5, we examine the reasons for the increase in mortality at age 62. We conclude in Section 6.

\section{Age 62 and Social Security Eligibility}

Social Security Retirement Insurance is available to older workers with ten or more years of Social-Security-taxable employment. ${ }^{6}$ While there was a single retirement age of 65 when Social Security was first established, the ability to claim at age 62 was established for women in 1956 and men in 1961. Age 65 became the FRA, the age at which workers would receive the full "Primary Insurance Amount" (PIA) due to them under the Social Security earnings-payment formula. Benefits were reduced by 5/9 of one percent for each month before the FRA that an individual began claiming Social Security, so that workers claiming in the month they turn 62 received 80 percent of their PIA. Cohorts born after 1942 have a FRA of 66 and receive 75 percent of their PIA if they claim immediately upon turning age $62 .^{7}$

Social Security Retirement and Survivors Insurance is also available to qualifying workers' dependents and survivors. These are most commonly a worker’s spouse, divorced spouse, or

\footnotetext{
${ }^{6}$ Workers need 40 credits that depend on annual earnings; in 2015, workers earning over $\$ 4,880$ received the maximum four credits. For more details about this and other SSA policies discussed in this section, see SSA (2012).

${ }^{7}$ Starting with the 1938 cohort, the FRA increased in two month increments, so the 1938 cohort has a FRA of 65 and 2 months, the 1939 cohort has a FRA of 65 and 4 months, etc. There is now an early claiming penalty of 5/9 of one percent per month for the first 36 months of early claiming and 5/12 of one percent for each additional month. There are also "Delayed Retirement Credits” for delaying Social Security claiming up to age 70.
} 
widow(er). ${ }^{8}$ Dependents' base level of benefits is up to 50 percent of the worker's PIA. Spouses (or former spouses) can receive Social Security benefits at age 62, when they receive 70-75 percent of their PIA-based benefits (depending on their FRA). Widow(er)s can receive benefits from age 60; again, there are reductions for claiming early. For our identification strategy, it is important to emphasize that only the claimant's age matters for benefit collection, not the age of the person upon whose record the benefit is being claimed. Therefore, there is no incentive to remain alive until age 62 so that one's spouse and/or dependents can collect benefits.

Individuals can file an application for Social Security several months before turning age 62. They become eligible for Social Security either in the month they turn 62 or the following month. ${ }^{9}$ As described in the introduction and shown in Figure 1, many people claim Social Security at the first possible opportunity, despite a penalty to claiming early. These are populationlevel rates, so the rates among workers with sufficient covered employment and their dependents are even higher. Men and women claim at similar rates at age 62, although women are more likely to claim as dependents and have an average monthly benefit that is 25 percent lower than male age-62 claimants (SSA, 2012). Compared to individuals who claim Social Security at later ages, both male and female age-62 claimants are less educated, in worse health, have had lower earnings, and been more likely to work in physically demanding jobs (Li, Hurd and Loughran, 2008).

Social Security beneficiaries are not required to stop working, though they are subject to a "Retirement Earnings Test" until they reach the FRA that reduces benefits by one dollar for every two dollars of earnings above a threshold, which is currently $\$ 15,720$ per annum. ${ }^{10}$ Even though beneficiaries later receive the benefits that are withheld, many beneficiaries appear to view the Retirement Earnings Test as a tax and reduce their labor force participation as a result (Friedberg, 2000; Gelber, Jones and Sacks, 2013). Most individuals do substantially decrease their employment after claiming Social Security at age 62, and also report immediate changes in retirement status, income and health insurance (Rust and Phelan, 1997; Gustman and Steinmeier, 2005; Li, Hurd and Loughran, 2008). We examine those changes in Section 5.

\footnotetext{
${ }^{8}$ Other dependents include children, adult children disabled before age 22, and parents who are reliant on the worker for income support. These groups are more commonly dependents of Social Security Disability Insurance beneficiaries.

${ }^{9}$ Individuals born on the $1^{\text {st }}$ or $2^{\text {nd }}$ of the month are eligible in the month they turn 62 , while other individuals are eligible in the month after they turn 62. See Olson (1999) and Evans and Moore (2011) for more details.

10 There are different rules for the year that a beneficiary reaches the FRA.
} 
Payments to Social Security beneficiaries cease the month after death. Family members, funeral homes and government agencies report deaths to SSA, and there are limited opportunities to delay reporting. Dependents can receive a lump-sum death benefit of \$255 if they live with the beneficiary or receive benefits from the beneficiary's record (SSA, 2012). Any change driven by such incentives should be most pronounced for married decedents. (In Section 4.3, we show that non-married males have a larger change in mortality when they reach 62 than married males.)

Any change in aggregate mortality at age 62 can be attributed to Social Security only if there are no other concurrent policy rules that affect health. To our knowledge, apart from some federal employee rules discussed in footnote 4, there are no other federal programs or pension policies with rules that change discontinuously at age 62. Private sector employers have largely switched to defined contribution pensions that provide little incentive to retire at a specific age (Dushi, Iams, and Lichtenstein, 2011). For the defined benefit programs used in the public sector, eligibility for a full pension is typically based on years of service (Friedberg, 2011). Although there may be some state-level policies with specific rules at age 62, we show our mortality estimates do not depend on a particular state or region.

\section{Data and Sample Characteristics}

The mortality data come from restricted-use versions of the National Center for Health Statistics' Multiple Cause of Death (MCOD) files for 1979 to 2012. The information in the MCOD files comes from death certificates compiled by state registries and include decedents' dates of birth and death; demographic information, including age, sex, race, marital status and educational attainment; and cause and place of death. ${ }^{11}$ Sex, race and place of residence in these data closely match survey data (Sorlie, Rogot and Johnson, 1992), while education levels are slightly higher than reported in other data (Sorlie and Johnson, 1996). Underlying cause of death is coded using the International Classification of Disease (Versions 9 and 10).

There may be a concern that the measurement of mortality changes with the receipt of Social Security, thereby introducing bias into our analysis. Two reasons suggest this is not the case. First, the Centers for Disease Control and Prevention (CDC) regard MCOD data as having universal coverage because state laws require death certificates for disposition of bodies and certificates are needed for legal purposes (e.g., estate settlement) (CDC, 1989). Second, the MCOD

\footnotetext{
${ }^{11}$ Educational attainment is available since 1989.
} 
files are not derived from SSA information; in fact, SSA pays states' vital statistics bureaus - the source of MCOD data - to provide it with death records in order to manage program payments. ${ }^{12}$

Given that age of death is our assignment variable, it is important to emphasize that the dates of birth and death are reported to the exact day. There is no odd heaping in the distributions of these dates, suggesting that any patterns in mortality counts based on age at death should not reflect reporting differences related to data collection. Such heaping in data is important to consider before implementing a RD design (Barreca, Lindo and Waddell, 2016).

In order to have sufficient bandwidth and the opportunity to conduct placebo tests at nearby ages, we focus on individuals born between 1921 and 1948 (i.e., turning 62 between 1983 and 2010). In Table 1, we show the number and composition of deaths in this group at ages 61 and 62 for all decedents, and separately for males and females. There are 65,489 deaths per month at age 61 and 70,727 deaths per month at age 62. Males account for approximately 60 percent of the deaths at both ages, well above their proportion of the population at these ages. The other demographic characteristics are broadly in line with general population characteristics, although it has been well documented that there is higher mortality at relatively young ages among those with characteristics related to low socioeconomic status, such as not completing high school and not being married (Sickles and Taubman, 1997).

We use three other datasets. The first is a one percent extract of administrative Social Security claiming data, used to create Figure 1. The second is the Health and Retirement Study (HRS), a nationally representative panel survey of Americans aged 50 and older. It contains information on demographic characteristics, employment, retirement plans, income and health outcomes. We use the RAND HRS File (Version N), a compilation that contains data from 1992 to 2012 on cohorts born between 1924 and 1959 (Chien et al., 2014). The third is accelerometer data from the National Health and Nutrition Examination Survey (NHANES) 2003-2006, which measures the health of the civilian population via interviews and physical examinations. More details about the samples and variables used from each dataset are provided in the appendix.

\footnotetext{
12 SSA also receives death reports from other sources (e.g., family members, funeral homes). The Social Security Act stipulates that SSA can only share its full mortality data with benefit-paying federal agencies (see 42 U.S.C. § 405(r)(3)). There is no evidence that the Social Security Master Death File, a limited public file, is used by state vital statistics bureaus or the NCHS. See the General Accountability Office (2013) for more information about SSA's mortality data.
} 


\section{The Change in Mortality at Age 62}

\subsection{Graphical Evidence}

We show the number of deaths for each month of age in Figure 2. We include counts for 12 months on each side of age 62 (i.e., ages 61 years, 0 months to 62 years, 11 months). Overall mortality counts are shown in Panel A. There is a large increase in mortality in the month individuals turn 62, with 1,580 more deaths in the month after turning 62 than the month before (a 2.4 percent increase). By comparison, the next largest difference in month-on-month mortality is less than one half of this magnitude. We also show lines estimated for each side of the age-62 cutoff using quartic polynomials. ${ }^{13}$ These indicate a discontinuous increase in mortality at 62; we formally test for such an increase in the next section. In the other panels of Figure 2, we show that this increase in monthly mortality occurs at age 62 for both males (Panel B) and females (Panel C), although there is a clearer and larger increase in mortality for males than females.

It is possible that this change in mortality is related to having a birthday or generally becoming one year older. To check this, Appendix Figure A1 shows the same age-in-months mortality counts in relation to ages 61 and 63. We are not aware of any important age-based policy rules at these ages. There is no obvious change in mortality at either of these ages, either for the full sample or for separate subsamples of males and females.

\subsection{Regression Estimates}

To estimate the mortality effects of Social Security eligibility at age 62, we use a RD design to compare the number of deaths of individuals aged just older than 62 to slightly younger individuals. Following other studies using age-based eligibility thresholds (e.g., Card, Dobkin and Maestas, 2009; Anderson, Dobkin and Gross, 2014), we seek to estimate the effect of an anticipated change in program eligibility. Comparing deaths above and below age 62 should generate estimates of the average treatment effect of Social Security eligibility on mortality as long as other factors affecting mortality do not change discontinuously when individuals turn 62 .

We implement several global parametric and local nonparametric RD specifications that allow us to assess the stability of the results under different assumptions about the data generat-

\footnotetext{
${ }^{13}$ Our specification is the default regression of Calonico, Cattaneo and Titiunik (2014b) for RD plots, which also is in line with recommendations by Lee and Lemieux (2010).
} 
ing process. The global parametric regressions contain polynomials that control for the underlying age-mortality relationship and a dummy variable to estimate the change in mortality at age 62. In our setting, the basic form of the regression is:

$$
\log \left(\text { Mortality }_{a}\right)=f(a)+{\text { Post } 62_{a} \beta+\varepsilon_{a}} .
$$

The dependent variable is the natural log of mortality counts for age at death $a$, which allows us to measure the change in mortality in percentage terms. We use monthly counts, which is the level of aggregation suggested by RD tests of excess smoothing (Lee and Lemieux, 2010). The function $f(a)$ represents the polynomials used to control for the relationship between age and mortality. We separately use quadratic, cubic and quartic polynomials, as there is a debate about what polynomial length should be used (Lee and Lemieux, 2010; Gelman and Imbens, 2014). The dummy variable Post $62_{a}$ is equal to one above age 62 and zero otherwise, and the coefficient $\beta$ gives the percentage change in mortality at age 62 (our coefficient of interest). We allow the relationship between age and mortality to vary on either side of the discontinuity by interacting Post $62_{a}$ with all of the polynomial terms. The error term is $\varepsilon_{a}$. We use robust standard errors clustered on age of death.

In column 1 of Table 2, we present the estimated change in mortality when individuals turn 62. We initially use a 12-month bandwidth. The point estimates for the different specifications are 1.35 percent (quadratic), 1.97 percent (cubic) and 1.93 percent (quartic). All are statistically significant at the one percent level. The relationship between age and log mortality increases slightly after age 62, although the relevant coefficients are not large or precisely estimated. ${ }^{14}$

We also use local nonparametric specifications to relax the functional form assumptions and place more weight the observations near the cutoff. We use the local linear and quadratic specifications of Calonico, Cattaneo and Titiunik (CCT) (2014a, 2014b), whose "data driven" bandwidth selection procedure is based on minimizing the mean square error of the point estimate. We start with 24 months of data on either side of age 62, as policies that take effect at age 60 could separately affect mortality. We report estimates that use a triangular kernel, CCT's procedures to correct for bias due to bandwidth choice, and plug-in residuals for standard error estimation, which are equivalent to Huber-White robust standard errors in the parametric context.

\footnotetext{
14 The full set of coefficients from the quadratic specification is presented in Appendix Table 1.
} 
The results from these regressions are also presented in the first column of Table 2, together with the bandwidths used. The estimates are similar to the parametrically generated results, with point estimates of 1.42 percent (local linear) and 1.94 percent (local quadratic) that are statistically significant at the one percent level. Across the five specifications and in accord with the visual evidence, we find a statistically significant increase in mortality at age 62.

In Table 2, we also present estimates of the change in mortality in the month individuals turn 62 separately for males (in column 2) and females (in column 3) using the three global parametric and two local nonparametric specifications. For males, the estimated increase in mortality is between 1.85 and 2.43 percent and always statistically significant at the one percent level. For females, the estimated increase in mortality is between 0.58 and 1.38 percent. All except the quadratic estimate are statistically significant at the one percent level; the quadratic estimate of 0.58 percent is not statistically different from zero at conventional levels. The results are in line with the visual evidence of a larger and clearer change in mortality for males than for females.

We verify that the estimates are robust to additional regression controls and other choices (Appendix Table A2). First, we show that the global parametric estimates are similar when yearof-birth or month-of-death fixed effects are included. Second, we show that the estimates are similar using daily or weekly mortality counts. Third, we present estimates where the cutoff is defined by the precise Social Security eligibility rules. These rules grant individuals born on the $1^{\text {st }}$ or the $2^{\text {nd }}$ of the month eligibility in the month they turn 62 , while others become eligible the following month (Olson, 1999). Our estimates are qualitatively similar throughout.

We next assess the robustness of the estimates to different bandwidths by using bandwidths of between six and 24 months. Having established that the results are generally similar with and without higher-order terms, in this and following exercises we focus on the local linear and global quadratic specifications. Appendix Figure A2 shows the estimates and 95 percent confidence intervals from both of these specifications for the full sample, for males and for females. For the full sample and for males, the local linear and global quadratic estimates are between 1.5 and 2.4 percent and statistically significant for all bandwidth values. The results for females are more sensitive to the choice of bandwidth. The estimated change in mortality declines as the bandwidth is increased and loses statistical significance at the five percent level at 11 months in the local linear regression and 12 months in the global quadratic regression. At larger bandwidths, the estimates for females are smaller and imprecisely estimated. 
There could be a concern that the change in male mortality is spurious and equally sized estimates could be found at nearby ages. We first deal with this via a permutation test based on randomization inference. We generate "placebo" estimates at monthly intervals for 60 months before and after age 62 (i.e., from age 57 to 67). Note that this range includes ages at which there are policy eligibility thresholds that could affect mortality, such as ages 60 and 65. In Figure 3, we compare the estimate for the month males turn 62 to the empirical cumulative distribution functions of the placebo estimates using the local linear (Panel A) and global quadratic (Panel B) specifications. Despite including estimates possibly not from true placebo locations, for both specifications the largest estimate is for the month males turn 62. In contrast, as shown in Appendix Figure A3, our age-62 estimates for females are not distinct from other estimates: approximately one quarter of the local linear estimates and one half of the global quadratic estimates are larger in absolute value than the estimate for the month females turn 62. A second approach, based on comparing overall model fit in the month individuals turn 62 to nearby ages, reinforces that there is something distinct about the age-62 change in mortality for males, but not females. ${ }^{15}$

The estimated increase in male mortality is extremely robust. The results suggest there a substantial number of "excess" deaths for males after age 62. For example, the 2.15 percent local linear estimate translates into 10,746 additional male deaths in the 12 months after turning 62 and 22,029 additional male deaths in the 24 months after turning 62 (relative to a counterfactual of no discontinuous change at age 62). These translate into averages of 384 and 787 extra deaths per cohort, respectively. The results for female are smaller in magnitude and sensitive to bandwidth and specification choice. Henceforth, we therefore focus on the increase in male mortality.

Apart from varying the bandwidth over a range with no other policy discontinuities, it is inherently difficult to determine how "local" this effect is. In particular, some might wonder if the visual evidence in Figure 2 suggests a dip in mortality just before age 62 and a corresponding increase just after age 62. We can add dummy variables to the global quadratic regression to understand the extent to which the results are driven by observations close to age 62. If we add individual dummy variables to the three months before reaching age 62 and the three months after, the coefficient (standard error) is 0.0247 (0.0145). This is equivalent to a so-called "donut hole"

\footnotetext{
${ }^{15}$ We compare R-squared when the discontinuity is at age 62 to placebo locations. Using the global quadratic specification and 12 months of data on each side of age 62, we show that the R-squared value is maximized at age 62 for males but not for females (where it is fourth-largest in the 24-month window). The results are presented in Appendix Figure A4.
} 
$\mathrm{RD}$ where three months on either side of the age 62 discontinuity are dropped. If we drop the observations instead of use dummy variables, the coefficient (standard error) is 0.0247 (0.0126). When we use weekly counts and additional dummy variables to provide finer information, we find some evidence of an additional increase in male mortality in the first week after turning 62 . However, even with these additional controls and using the quadratic, cubic or quartic specifications, the overall change in male mortality at age 62 remains approximately two percent. (These results are shown in Appendix Table A3.) In combination with the stability of the estimates to bandwidth choice, these results suggest that the increase in male mortality persists for some time after males turn age 62 .

\subsection{Heterogeneity of Mortality Effects}

We now analyze heterogeneity across demographic subgroups. We continue to focus on estimates produced from the local linear regression with CCT bandwidth and global quadratic regression using a bandwidth of 12 months. Note that any difference across these groups could reflect differences in Social Security claiming or labor force participation, or how such changes affect mortality through, for example, healthy behaviors or access to health insurance. We will discuss the heterogeneity in the mortality effects in this section, and then seek to understand the likely cause of observed differences in the next.

We first check if the increase in male mortality is driven by a specific region of the US by omitting observations from each of the four Census regions in turn. These results are presented in Appendix Table A4. For each of the samples, the coefficients are similar to the main estimates and statistically significant at least at the five percent level. These results rule out state- or region-specific factors accounting the change in male mortality at age 62 .

We next examine the effects across cohorts or periods of time. Recall that the change in the FRA from 65 to 66 years increased the penalty due to claiming at age 62 from 20 to 25 percent, lowering average Social Security payments. However, as shown in Appendix Table A5, there is no discernible difference in the estimates across cohorts with different FRAs. This also shows that the increase in male mortality upon reaching age 62 is a persistent phenomenon that remains present in recent years.

We next consider the results for a range of demographic characteristics, which are presented in Table 3. In addition to the local linear and global quadratic estimates, we also report the fraction of total deaths that each group represents. Marital status is presented first. Given that 65 
percent of the decedents were married, we initially divide the sample into married and non-married males. For married males, the local linear estimate is 1.30 percent $(\mathrm{p}<0.05)$ and the global quadratic estimate is an imprecise 0.81 percent ( $\mathrm{p} \geq 0.05$ ). In contrast, estimates for non-married males are substantially larger, with a local linear estimate of 4.15 percent $(\mathrm{p}<0.01)$ and a global quadratic estimate of 3.77 percent $(\mathrm{p}<0.01)$. We can reject the null hypothesis that the coefficients for married and non-married males are the same $(\mathrm{p}<0.05)$. We examine the non-married group in further detail by looking separately at single, divorced and widowed males. The local linear and global quadratic point estimates for single males are the largest (5.14 and 5.58 percent), followed by divorced (3.05 and 3.37 percent) and widowed males (2.62 and 3.30 percent). Estimates for single and divorced males are statistically significant (at least) at the five percent level, but not for widowed males, although they only account for 6.2 percent of the sample. The only statistically significant difference between coefficients is between the single and married male coefficients $(\mathrm{p}<0.01)$.

We next present results based on differences in educational attainment. Note that the sample is smaller because educational attainment has only been available in the MCOD file since 1989. The increase in mortality upon turning 62 is largest for males who did not complete high school, with a local linear estimate of 3.03 percent $(\mathrm{p}<0.01)$ and a global quadratic estimate of 2.75 percent $(\mathrm{p}<0.05)$. The estimates for those who completed high school and those who completed college are smaller and not statistically significant at any level, although the standard errors for college males are large and 95 percent confidence intervals do not rule out large increases in mortality at age 62 . We cannot reject the null hypothesis that the coefficients are the same.

Race is defined broadly as either white or non-white, as non-white males only account for 16.5 percent of the sample. For white males, the estimates are large (2.09 and 2.37 percent) and statistically significant (both $\mathrm{p}<0.01$ ). For non-white males, the estimates are smaller (0.68 and 0.78 percent) and not statistically significant; however, the confidence intervals are wide and do not rule out a similar increase in mortality as for white males.

We examine if there are differences by place of death, using three categories: in-hospital deaths; deaths in nursing homes/institutions; and other deaths (including deaths classified as “dead on arrival” at hospital). The largest increase upon turning 62 occurs for deaths outside of hospitals/institutions, with estimates of 3.23 and 3.39 percent (both $\mathrm{p}<0.01$ ). Deaths in hospitals 
are estimated to increase by 1.24 and 1.30 percent (both $\mathrm{p} \geq 0.05$ ), while deaths in nursing homes and other institutions change by -0.22 and -0.79 percent (both $\mathrm{p} \geq 0.05$ ). The lack of any change in mortality in long-term care facilities is consistent with our hypothesis, as an increase in this group would have suggested a mechanism unrelated to changes in Social Security.

The heterogeneity across demographic groups may represent underlying differences in Social Security claiming or associated changes in individuals' work, income and health insurance coverage. We next combine this evidence with information on retirement-related changes to understand why mortality increases once males turn 62.

\section{Why Does Male Mortality Increase at Age 62?}

Claiming Social Security is not an isolated event; many other changes commonly occur at the same time. First, individuals frequently stop working or reduce work levels. Second, health insurance status can change as - upon stopping employment - employer-sponsored health insurance ceases or is more expensive under continuing-coverage mandates. (Medicare is unavailable until age 65.) Third, income can change at age 62 due to the arrival of Social Security income and the reduction in earnings. ${ }^{16}$ Each change potentially has detrimental health consequences.

Given the lack of direct information in the MCOD data, we use complementary data sources and previous literature to provide descriptive evidence as to which of these are likely to be important in explaining the rise in mortality at age 62. Our analysis proceeds in three steps. First, we document the retirement-related changes that occur at age 62. Second, using the heterogeneity in the mortality estimates across demographic subgroups, we examine which of these retirement-related changes at age 62 are most strongly correlated to changes in mortality. As a result of these exercises, decreasing labor force participation emerges as the most likely reason mortality rises at age 62. Finally, we examine cause-of-death results and information on health behaviors and show it is plausible that labor force exit could explain our mortality results.

\subsection{What Changes at Age 62 as a Result of Social Security Claiming?}

We examine retirement-related changes using the Health and Retirement Study (HRS), which is focused on aging and retirement information. We first establish what changes occur at

\footnotetext{
${ }^{16}$ It is unlikely that the timing of income receipt plays any role. Evans and Moore (2011) show that there is a short-term increase in mortality following the receipt of income (including for Social Security income). However, this phenomenon is unlikely to account for the observed change in mortality at age 62 as the increases in mortality they identify are primarily present in the first week after income receipt and largely offset by declines in mortality three or four weeks afterwards. Our use of monthly mortality counts means such fluctuations are unlikely to drive the variation in our main estimates.
} 
age 62 by plotting various outcomes in Figure 4. Age is measured in quarters and rates are calculated using person-specific sample weights. Claiming is self-reported and retrospective. In Panel A and B, we show the respective Social Security claiming rates for male and females. As for the mortality data, we show lines estimated for each side of the age-62 cutoff using quartic polynomials. We also show the coefficient (standard error) from the global quadratic RD regression used previously, which is 0.206 (0.007) for males and $0.204(0.009)$ for females. If we estimate the change using the SSA data for Figure 1, we find similar, albeit slightly higher discontinuities in overall Social Security claiming for males and females. ${ }^{17}$

We present other outcomes in the rest of Figure 4. We show the fraction of males and females retired in Panel C and D, respectively, where retirement is defined by labor force status (i.e., not working due to retirement). Male retirement is estimated to increase discontinuously at age 62 by 10.9 p.p. $(\mathrm{p}<0.01)$, compared to 4.7 p.p. for females ( $\mathrm{p} \geq 0.05)$. Two other employment outcomes are shown: labor force participation (in Panels E and F) and the fraction working for pay (in Panels $\mathrm{G}$ and $\mathrm{H}$ ). Male labor force participation is estimated to change discontinuously at age 62 by -8.2 p.p. $(\mathrm{p}<0.01)$, while there is no change in female labor force participation $(-0.5$ p.p., $\mathrm{p} \geq 0.05$ ). The fraction of males working for pay is estimated to change discontinuously at age 62 by 8.2 p.p. $(\mathrm{p}<0.01)$ and remain unchanged for females $(-0.9$ p.p., $p \geq 0.05)$. For all three measures of labor supply, males experience large and statistically significant changes upon turning 62, while the estimated changes for females are small and imprecisely estimated.

We examine changes in health insurance coverage upon reaching age 62 in Panels I and J of Figure 4. For both males and females, the fraction with health insurance is steady and the estimated changes are statistically insignificant estimates of -1.4 and -1.7 p.p., respectively. Finally, we present annual household income in Panel K and L of Figure 4. HRS respondents are asked about their income in the previous calendar year, so we cannot examine age on a quarterly basis. We convert income to 2014 dollars using the CPI-U and plot it in terms of the respondents' age in the previous year (e.g., 63 year old respondents have their income for the previous year assigned to age 62 using CPI for that previous year). There is no change in household income trends at age 62 or 63, the first full year that Social Security would be a major income source for those claiming at age 62.

\footnotetext{
${ }^{17}$ Using the SSA data, the estimated discontinuities in claiming at age 62 for males and females are, respectively, 23.3 and 25.1 percentage points. It is not surprising that there is some measurement error in self-reported Social Security claiming rates in the HRS; it is unlikely this differs by sex. We also use alternate measures of claiming in the demographic analysis.
} 
While Social Security claiming and increases at age 62, the changes in claiming are similar for males and females, making it unlikely to be the reason why males have a large and robust increase in mortality. However, male changes in labor force participation are much larger than those of females. Therefore, decreasing labor force participation emerges as the most likely explanation for why males’ mortality increases upon turning 62.

\subsection{The Relationship between Changes at Age 62 and the Mortality Effects}

We make use of demographic information common to both MCOD and HRS data to further explore the role of Social-Security-related changes at age 62. In Section 4.3, we estimated male mortality for subgroups based on marital status (married, single, divorced and widowed), educational attainment (completed less than high school, high school graduate and college graduate) and race (white and nonwhite). Using these characteristics, we create 13 distinct male subgroups with reasonable sample sizes in both the MCOD and HRS files. ${ }^{18}$ For 14 groups (females plus 13 male groups), we compare the changes in retirement-related outcomes upon turning 62 to changes in mortality. We use the global quadratic RD specification.

In Figure 5, we examine the relationship between the mortality estimates and the same six retirement-related outcomes used in Figure 4: Social Security claiming, fraction retired, fraction in labor force, fraction working for pay, fraction with health insurance and average household income. For each of the 14 groups, the mortality coefficients are plotted in relation to the horizontal axis and the estimated changes in the retirement-related outcomes are plotted in relation to the vertical axis. The linear relationship between the coefficients is also plotted.

The strongest correlations are between the size of the mortality estimates and the three work-related outcomes. Mortality changes are positively correlated with the changes in retirement and negatively correlated with changes in labor force participation and working for pay. We assess the strength of these relationships by separately regressing the mortality estimates on each of these outcomes. We do this with and without weighting by the average number of deaths in each group to reflect their contribution to the aggregate mortality effects (Solon, Haider and Wooldridge, 2015). As shown in Appendix Table A6, the coefficients are similar with and without weighting and all are statistically significant at the five percent level. The results suggest that

\footnotetext{
${ }^{18}$ While the combination of these characteristics provides a possible 24 male subgroups (4 marital x 3 education x 2 race types), sample sizes in some subgroups are very small. Instead, we aggregate some of these groups so there at least 200 HRS respondents within 24 months of age 62. This is achieved by creating six married subgroups (split by both education and race), three subgroups each for single and divorced males (split by education only), and a widower subgroup.
} 
decreases in labor force participation are correlated with increases in mortality. The point estimates suggest that a one percentage point decrease in the three employment outcomes raise mortality by approximately 0.07-0.1 percent.

In contrast, the relationship between the changes in Social Security claiming and mortality at age 62 appears weak visually and is not statistically significant at conventional levels in either regression. To ensure this is not due to the specific way Social Security claiming is measured in the HRS, we consider mean differences in claiming rates between ages 61 and 62, and the receipt of Social Security payments as alternate measures. ${ }^{19}$ As shown in Appendix Table A6, there is no relationship between the mortality estimates and either measure.

Finally, we consider the role of changes in health insurance and income upon turning 62. The figures and the regressions suggest there is no relationship between these outcomes and the mortality estimates. ${ }^{20}$ This is unsurprising given that, as shown in Figure 4, these outcomes do not change at age 62. In the regression analysis, we also show that there is no relationship with alternate measures, including the number of health insurance plans a respondent has and household income when it is restricted to respondents interviewed between January and March (whose calendar income will more closely match their age-related income).

\subsection{Underlying Causes of Death and Changes in Health Behaviors}

The increase in mortality at age 62 appears related to changes in labor force participation, although it is not possible to establish a direct causal relationship. To further examine the plausibility of this mechanism, we examine which causes of death increase when males turn 62 and consider the connection between those causes and decreased employment. We use underlying causes of death across International Classification of Disease Versions 9 and 10, defining four groups and examining subgroups as sample sizes allow. The groups are: (i) heart and lung conditions; (ii) cancers; (iii) external causes; and (iv) all other causes. More details about this classification are provided in the appendix; we provide estimation results in Appendix Table A7.

\footnotetext{
${ }^{19}$ There is measurement error in self-reported Social Security claiming rates in the HRS at the monthly level; the increase at 62 observed in the SSA data is spread slightly over nearby months. As a result, as can be observed in Panel A of Figure 5, the estimated discontinuities for the 14 groups are smaller than might be estimated if administrative data had been available; however, the SSA data do not include the relevant demographic information. As an alternate measure, the difference in the average claiming rates at ages 61 and 62 overstates the change immediate after turning 62, but yields similar results. The receipt of Social Security payments is another, albeit coarse measure that is available in the HRS.

${ }^{20}$ Annual income data means it is not possible to use the $\mathrm{RD}$ specification, so we report the average percentage change in income between ages 61 and 63 on the vertical axis.
} 
The local linear and global quadratic RD estimates for heart and lung conditions are 1.35 and 2.50 percent, with the latter statistically significant $(\mathrm{p}<0.05)$. This group consists of heart attacks, other heart disease, chronic obstructive pulmonary disease (COPD) and strokes. When it is separated into heart attacks, COPD and other heart/lung causes, the increase for COPD (4.96 and 6.96 percent, $\mathrm{p}<0.05$ and $\mathrm{p}<0.01$ respectively) is striking. In contrast, the point estimates for heart attacks and other heart/lung causes are smaller and not statistically significant.

A large, statistically significant increase is present for cancer (2.62 and 2.63 percent, $\mathrm{p}<0.01$ for both specifications). While it may seem strange that there is a discontinuous change in cancer at age 62, there can be many other causes of death in addition to the primary cause. When we restrict the sample to cases where cancer was the only identified cause of death, the estimated change is smaller and not statistically significant ( 0.69 and 1.78 percent, both $\mathrm{p} \geq 0.05$ ). Once we separately estimate the change for lung cancer and other cancers (whether or not they were the only identified cause), it is clear that the increase at age 62 is due to a large increase in lung cancer deaths (5.10 and 5.31 percent, both $\mathrm{p}<0.01$ ). In contrast, the estimated increase in other cancers is 0.99 and 1.06 percent (both $\mathrm{p} \geq 0.05$ ).

External causes, which consists accidents, murders, and suicides, increase at age 62 (3.14 and 3.99 percent, $\mathrm{p}<0.01$ and $\mathrm{p}<0.05$ respectively). This is due to a large, statistically significant increase in motor vehicle fatalities (14.21 and 15.26 percent, both $\mathrm{p}<0.01$ ). However, it is important to note that this group accounts for 1.3 percent of all male deaths at these ages, so that traffic fatalities account for no more than 10 percent of the overall increase in male mortality at age 62. There is no increase in non-motor-vehicle external cause deaths (-0.88 and 0.07 percent, both $\mathrm{p} \geq 0.05$ ). Finally, other deaths (i.e., not classified as heart-/lung-related, cancers or external causes) account for 22 percent of all deaths. There is a small, statistically insignificant increase in deaths at age 62 within this group ( 1.09 and 1.13 percent, both $\mathrm{p} \geq 0.05$ ).

The coefficient estimates and fraction of deaths suggest that the three causes with statistically significant increases in the month males turn 62 - COPD, lung cancer and traffic accidents - account for slightly less than half of the overall increase in male mortality at age 62. Many of the other coefficients are positive, but not statistically significant at conventional levels. 
Increases in COPD and lung cancer suggest that males' respiratory-related mortality risks change at age $62 .{ }^{21}$ Important risks for these conditions include smoking (Godtfredsen et al., 2008) and a lack of physical activity (Lee, Sesso and Paffenbarger, 1999); these affect mortality even in the short term and even when focusing on those already with the condition (Young et al., 2009; Waschki et al., 2011). What is the evidence for how these factors change with retirement? For smoking, a directly relevant study is Ayyagari (2016), who uses Social Security eligibility at age 62 to estimate the effect of retirement on smoking in the HRS. She finds smoking increases at 62 among those who had ever smoked, although the results are sensitive to the specification used. The increase is largest among those working before age 62, which is consistent with labor force participation being a relevant change at age 62. Furthermore, Falba et al. (2005) and Black, Devereux, and Salvanes (2015) show that smoking increases after job loss, providing further evidence that smoking behavior is related to changes in labor force participation.

Evidence on how physical activity changes after retirement is mixed, although a consistent result is that retirees become more sedentary, often watching more television (Evenson et al., 2002; Barnett et al., 2014). Time being sedentary is positively correlated with mortality, even when accounting for exercise levels (Koster et al., 2012, Matthews et al., 2012). In Appendix Figure A5, we show that males increase the time they are sedentary during work hours increases by approximately 15 percent at age 62 (while there is no change in sedentariness of females). ${ }^{22}$

Our findings are consistent with evidence that job loss increases respiratory-related mortality and traffic fatalities. ${ }^{23}$ Eliason and Storrie (2009a) use administrative data to examine the mortality effects of large layoffs in Sweden. They find that male mortality increases after job loss, but there is no change for females. The largest increases are for lung cancer, external causes, and circulatory conditions. While they do not examine traffic fatalities, in a related paper on hospitalizations they find traffic-related hospitalizations rise among males who lost their job

\footnotetext{
${ }^{21}$ There are many common risk factors for COPD and lung cancer, and their presence is highly correlated; 50-70 percent of patients diagnosed with lung cancer suffer from COPD, and COPD often precedes a lung cancer diagnosis (Young et al., 2009). That the rise in cancer deaths occurs among those with lung cancer and additional recorded causes of death also suggests that similar factors may account for the rises in these categories.

${ }^{22}$ We use data on the intensity of physical activity from NHANES 2003-2006, as some participants wore accelerometers for a week. Males were sedentary 59 and 60 percent of the time at ages 60 and 61, respectively, then 67 and 65 percent at ages 62 and 63. If we focus on 8am-6pm Monday to Friday (i.e., standard work times) the fraction of time that males are sedentary increases by 15 percent at age 62, compared to changes of one and five percent at ages 61 and 63 . There is no equivalent change at age 62 for males outside of these hours, or in the fraction of time that females are sedentary. While sample sizes are small (92 males and 87 females), the patterns suggest that males' sedentariness may change at age 62.

${ }^{23}$ Some relevant studies, such as Snyder and Evans (2006) and Sullivan and von Wachter (2009), either do not examine different causes of death or do not have precise estimates by cause of death.
} 
(Eliason and Storrie, 2009b). Browning and Heinesen (2012), using Danish administrative data, also find that male mortality increase after large layoffs. The largest increases are for traffic fatalities, circulatory conditions and suicides, but not cancers. Bloemen, Hochguertel and Zweerink (2015) find that, in the Netherlands, males laid off due to plant closures have a higher probability of dying within five years as a result of rises in cardiovascular diseases and smoking-related cancers. Among the studies investigating the mortality effects of retirement, only Kuhn, Wuellrich, and Zweimüller (2010) find differences by cause of death. They find that increases in male mortality resulting from unemployment-insurance-related retirements in Austria are due to increases in heart attacks, traffic fatalities, and diseases related to excessive alcohol use and smoking. In combination, these studies show that the causes of death that change discontinuously at age 62 are similar to ones that increase when males lose their jobs.

\subsection{Evaluating the Mortality Effects of Retirement at Age 62}

Our analysis and the supporting evidence suggests decreasing labor force participation is a key factor in rising mortality when males turn 62, although it is not possible to establish causality or rule out other factors. ${ }^{24}$ If decreased labor force participation is the reason, then it is important to adjust our estimates to account for the fact that only some males stop work at age 62 . The aggregate mortality results can be thought of as intent-to-treat estimates; we now use observed changes in work to estimate the treatment effect of retirement on mortality at age 62 . We do so by dividing the $\mathrm{RD}$ estimate for the percentage change in male mortality upon turning 62 by equivalent $\mathrm{RD}$ estimates of the percentage point change in work activity. We use the global quadratic RD specification in the same way as before and calculate a standard error for this ratio using the delta method (e.g., similar to Anderson, Dobkin and Gross, 2014).

As with our previous analysis, we use the HRS to estimate the change in retirement, labor force participation and working for pay at age 62. Results are reported in Appendix Table A8. If the 1.9 percent increase in overall male mortality is attributed to the 11 percentage point increase in retirement, then this discontinuous change in retirement results in a 17 percent increase in mortality. Similarly, males have an 8.2 percentage point decline in both labor force participation

\footnotetext{
${ }^{24}$ There are other ways that exiting the workforce could affect health. For example, social isolation can increase upon retiring and has been shown to be correlated with higher mortality (Pantell et al., 2013). The relatively large increase in the mortality of non-married males is certainly consistent with this type of change, although social connections are not the only difference between married and non-married males (e.g., Ayyagari (2016) finds that smoking at age 62 increases more among non-married than married HRS respondents).
} 
and the fraction working for pay at age 62. Attributing the increase in aggregate male mortality to either of these measures suggests that stopping work elevates mortality by 23 percent. All three of these estimates are statistically significant at the one percent level.

We estimate similar ratios for females. The estimated changes in females' retirement, labor force participation and the number working for pay when they turn 62 are, respectively, 4.2, 0.1 and -0.8 percentage points. Attributing the 0.6 percent rise in overall female mortality to these measures leads to imprecise estimates of the increase in mortality of 14 percent (for retirement), 402 percent (for labor force exit) and 72 percent (for stopping work). The standard errors on these estimates are extremely large; it is possible there is no relationship between these work activity measures and female mortality, but it is also possible the relationships are of a similar size to what we precisely estimate for males. The availability of Social Security at age 62 does not generate a “first stage” effect on females' employment, making it impossible to say whether or not the connection between retirement and mortality is specific to males.

Results for the different work-related outcomes suggest that retirement in this setting increases males' mortality risks by approximately 20 percent. This is comparable to related studies. For example, among Austrian blue collar UI recipients in their late 50s, Kuhn, Wuellrich, and Zweimuller (2010) estimate that labor force exit elevates mortality by 13 percent. Sullivan and von Wachter (2009) examine the mortality effects of involuntary unemployment on males using plant closures in Pennsylvania. They estimate that mortality risks increases by over 50 percent in the first year following a layoff, and are 10-15 percent higher even 20 years after displacement. The studies examining involuntary job loss in Europe that were discussed in the previous section find mortality increases of 30-80 percent in the first year after job loss, and persistent effects in subsequent years. ${ }^{25}$ We do not expect exactly the same estimates, as these studies generally examine involuntary job loss, whereas we are examining voluntary exit induced by the availability of Social Security. However, these other studies demonstrate that large and immediate changes in mortality are possible when there are abrupt changes in male labor force participation.

\footnotetext{
${ }^{25}$ Browning and Heinesen (2012) estimate that the mortality of Danish males laid off increases by 80 percent in the first year and is 10 percent higher over a 20-year span. Eliason and Storrie (2009a) estimate that males laid off in Sweden increases their mortality by 44 percent over the first four years, and nothing thereafter. Bloemen, Hochguertel and Zweerink (2015) find that males laid off in the Netherlands have a 34 percent higher probability of dying within five years.
} 
A 20 percent increase in mortality translates into potentially large decreases in life expectancy for males who retire from the labor force upon reaching 62 . The existence of policy discontinuities at other ages makes it difficult to extrapolate our estimates too far from age 62, although our estimates are reasonably robust to bandwidth choice. ${ }^{26}$ If the increase in male mortality due to labor force exit persisted at similar levels, then our results suggest that the life expectancy of males stopping work at age 62 may be reduced by as much as 1.5 years. ${ }^{27}$ Of course, policy-relevant increases to the Social Security EEA are likely to be bounded by the FRA, which is currently 66 years. Assuming that mortality is elevated by 20 percent for four years (i.e., until age 66) leads to an estimated decrease in life expectancy of three months among males exiting the labor force because Social Security is available.

\section{Conclusion}

Mortality is an important, well-measured, objective health outcome. The availability of detailed administrative data on the entire U.S. population and a strong claiming response to Social Security eligibility provides an opportunity to examine how Social Security and retirementrelated behaviors affect an objective health outcome. We present evidence of a two percent increase in overall male mortality when they turn 62 . This change is statistically significant and robust to different modeling choices, including the range of mortality data used.

The estimated increase is largest for unmarried males and males with low education levels. While these demographic groups do not necessarily experience the largest rates of claiming Social Security at age 62, they do have the largest changes in terms of labor force exit. The causes of death with the clearest increases at age 62 are traffic accidents and two lung-related conditions: COPD and lung cancer. These causes of death have previously been found to be related to job loss, and there is also suggestive evidence that males engage in more unhealthy behaviors once they retire. In combination, the results point to decreased labor force participation

\footnotetext{
${ }^{26}$ While there are age-based policy rules beyond these ranges, the results appear reasonably stable at even larger bandwidths. For example, with a five-year bandwidth, the RD global quadratic coefficient (standard error) on the change in aggregate male mortality at age 62 is estimated to be 0.020 (0.003). When we combine this estimate with the estimated changes in the three measures of work activity using a five-year bandwidth, the point estimates for the implied increase in male mortality due to exiting the labor force lie between 23 and 26 percent (with $\mathrm{p}<0.01$ in all cases).

${ }^{27}$ Recent SSA life tables and mortality rates are provided by the SSA Office of the Chief Actuary (available at: http://www.ssa.gov/oact). We estimate that, for the extra 10 percent of males who retire in the month they turn 62 , a 20 percent increase in mortality rates reduce life expectancy by 1.49 years. If the elevated mortality is assumed to only last for four years (i.e., through to age 66), we find that male life expectancy is decreased by 0.26 years.
} 
upon turning 62 as a key reason for a discontinuous increase in male mortality. Our results suggest that increases to the age at which Social Security available - or other changes that encourage work among males sensitive to this threshold - may increase life expectancy by several months.

Some limitations are important to keep in mind when interpreting the results. First, it is important to reiterate that age 62 is a well-understood eligibility threshold, and therefore we are estimating changes in mortality from a policy that is anticipated. As a result, our estimates are of the effects on mortality net of any anticipatory changes in health investments. Second, it is not possible to establish whether the mortality effects estimated here would apply to individuals claiming Social Security at later ages, especially as age-62 claimants are less healthy, on average, than later claimants. Third, the structure of the empirical approach means that we are estimating an effect that is difficult to extrapolate too far from age 62. It is not possible to establish whether age-62 Social Security claimants have elevated mortality over the longer term while they are receiving Social Security or if the health effects compound over time, although the estimates are stable over the range of data we use and evidence from the literature on the mortality effects of involuntary job loss show that persistent effects are possible. Fourth, the increases in mortality may not translate into broader health changes. Finally, any welfare losses related to heightened mortality risks may be offset by the utility gains related to stopping work. Further research will be required to understand the importance of these issues. 


\section{References}

Angrist, Joshua D., and Jorn-Steffen Pischke. 2014. Mastering Metrics: The Path from Cause to Effect. Princeton, NJ: Princeton University Press.

Anderson, Michael, Carlos Dobkin, and Tal Gross. 2012. The Effect of Health Insurance Coverage on Use of Medical Services. American Economic Journal: Economic Policy, 4(1):1-27.

Anderson, Michael L., Carlos Dobkin, and Tal Gross. 2014. The Effect of Health Insurance on Emergency Department Visits: Evidence from an Age-Based Eligibility Threshold. Review of Economics and Statistics, 96(1):189-195.

Ayyagari, Padmaja. 2016. The Impact of Retirement on Smoking Behavior. Eastern Economic Journal, 42:270-287.

Baker, Michael, Mark Stabile and Catherine Deri. 2004. What do Self-reported, Objective, Measures of Health Measure? Journal of Human Resources, 39(4):1067-1093.

Barnett, Inka, Esther van Sluijs, David Oglivie, et al. 2014. Changes in Household, Transport and Recreational Physical Activity and Television Viewing Time across the Transition to Retirement. Journal of Epidemiology and Community Health, 68(8):747-53.

Barreca, Alan I., Jason Lindo, and Glen R. Waddell. 2016. Heaping-induced Bias in RegressionDiscontinuity Designs. Economic Inquiry, 54(1): 268-293.

Behaghel, Luc, and David M. Blau. 2012. Framing Social Security Reform: Behavioral Responses to Changes in the Full Retirement Age. American Economic Journal: Economic Policy, 4(4):1-30.

Behncke, Stefanie. 2012. Does Retirement Trigger Ill Health? Health Economics. 21: 282-300.

Black, Sandra E., Paul J. Devereux and Kjell G. Salvanes. 2015. Losing Heart? The Effect of Job Displacement on Health. ILR Review, 68(4):833-861.

Bloemen, Hans, Stefan Hochguertel and Jochem Zweerink. 2013. The Causal Effect of Retirement and Mortality: Evidence from Targeted Incentives to Retire Early. IZA Paper 7570.

Bound, John. 1991. Self-reported versus Objective Measures of Health in Retirement Models. Journal of Human Resources, 26(1):106-138.

Bound, John, and Timothy Waidmann. 2007. Estimating the Health Effects of Retirement. Michigan Retirement Research Consortium Working Paper 2007-168.

Browning, Martin, and Eskil Heinesen. 2012. Effect of Job Loss due to Plant Closure on Mortality and Hospitalization. Journal of Health Economics, 31(4):599-616. 
Calonico, Sebastian, Mattias Cattaneo, and Rocio Titiunik. 2014a. Robust Nonparametric Confidence Intervals for Regression-Discontinuity Designs. Econometrica, 82(6):2295-2326.

Calonico, Sebastian, Mattias Cattaneo, and Rocio Titiunik. 2014b. Robust Data-Driven Inference in the Regression-Discontinuity Design. Stata Journal, 14(4):909-946.

Card, David, Carlos Dobkin, and Nicole Maestas. 2008. The Impact of Nearly Universal Insurance Coverage on Health Care Utilization: Evidence from Medicare. American Economic Review, 98(5):2242-58.

Card, David, Carlos Dobkin, and Nicole Maestas. 2009. Does Medicare Save Lives? Quarterly Journal of Economics, 124(2):597-636.

Centers for Disease Control and Prevention. 1989. Mortality Data from the National Vital Statistics System. Morbidity and Mortality Weekly Report, 38(8). Washington DC: CDC.

Charles, Kerwin K. 2004. Is Retirement Depressing?: Labor Force Inactivity and Psychological Well Being in Later Life. Research in Labor Economics, 23:269-299.

Chien, Sandy, Nancy Campbell, Ola Hayden, et al. 2014. RAND HRS Data Documentation, Version N. Santa Monica, CA: RAND Corporation.

Coe, Norma B., and Maarten Lindeboom. 2008. Does Retirement Kill You? The Evidence from Early Retirement Windows. IZA Discussion Paper No. 3817.

Coe, Norma B., and Gema. Zamarro. 2011. Retirement Effects on Health in Europe. Journal of Health Economics, 30(1):77-86.

Dave, Dhaval, Inas Rashad, and Jasmina Spasojevic. 2008. The Effects of Retirement on Physical and Mental Health Outcomes. Southern Economic Journal, 75(2): 497-523.

Dushi, Irena, Howard M. Iams, and Jules Lichtenstein. 2011. Assessment of Retirement Plan Coverage by Firm Size, Using W-2 Tax Records. Social Security Bulletin, 71(2): 53-65.

Eibich, Peter. 2014. The Health Effects of Retirement. DIW Roundup No. 48. Berlin: DIW.

Eliason, Marcus, and Donald Storrie. 2009a. Does Job Loss Shorten Life? Journal of Human Resources, 44(2): 277-302.

Eliason, Marcus, and Donald Storrie. 2009b. Job Loss is Bad for Your Health: Swedish Evidence on Cause-specific Hospitalization following Involuntary Job Loss. Social Science and Medicine, 68(8): 1396-1406.

Evans, William N., and Timothy J. Moore. 2011. The Short-term Mortality Consequences of Income Receipt. Journal of Public Economics, 95(11-12): 1410-1424. 
Evenson, Kelly R., Wayne D. Rosamond, Jianwen Cai, et al. 2002. Influence of Retirement on Leisure-time Physical Activity: The Atherosclerosis Risk in Communities Study. American Journal of Epidemiology, 155(8): 692-699.

Falba, Tracy, Hsun Mei Teng, Jody L. Sindelar, and William T. Gallo. 2005. The Effect of Involuntary Job Loss on Smoking Intensity and Relapse. Addiction, 100(9): 1330-1339.

Friedberg, Leora. 2000. The Labor Supply Effects of the Social Security Earnings Test. Review of Economics and Statistics, 82(1): 48-63.

Friedberg, Leora. 2011. Labor Market Aspects of State and Local Retirement Plans: A Review of Evidence and a Blueprint for Future Research. Journal of Pension Economics and Finance, 10(2): 337-361.

Gelber, Alexander, Damon Jones and Daniel Sacks. 2013. Earnings Adjustment Frictions: Evidence from the Social Security Earnings Test. NBER Working Paper 19491.

Gelman, Andrew and Guido Imbens, 2014. Why High-order Polynomials Should Not Be Used in Regression Discontinuity Designs. NBER Working Paper 20405.

Godtfredsen, Nina S., Tai H. Lam, Trevor T. Hansel, et al. 2008. COPD-related Morbidity and Mortality after Smoking Cessation: Status of the Evidence. European Respiratory Journal, 32(4): 844-853.

Gustman, Alan, and Thomas Steinmeier. 2005. The Social Security Early Retirement Age in a Structural Model of Retirement and Wealth. Journal of Public Economics, 89(2-3): 441-63.

Hallberg, Daniel, Per Johansson and Malin Josephson. 2015. Is an Early Retirement Offer Good for Your Health? Quasi-experimental Evidence from the Army. Journal of Health Economics, 44: 274-285.

Hernaes, Erik, Simen Markussen, John Pigott and Ola Vestad. 2013. Does Retirement Age Impact Mortality? Journal of Health Economics, 32: 586-598.

Idler, Ellen L., and Yael Benyamini. 1997. Self-rated Health and Mortality: A Review of Twenty-seven Community Studies. Journal of Health and Social Behavior, 38: 21-37.

Insler, Michael. 2014. The Health Consequences of Retirement. Journal of Human Resources, 49(1): 195-233.

Koster, Annemarie, Paolo Caserotti, et al. 2012. Association of Sedentary Time with Mortality Independent of Moderate to Vigorous Physical Activity. PLoS ONE 7(6): e37696.

Kuhn, Andreas, Jean-Philippe Wuellrich and Josef Zweimüller. 2010. Fatal Attraction? Access to Early Retirement and Mortality. IZA Discussion Paper 5160. 
Lee, David S. and Thomas Lemieux. 2010. Regression Discontinuity Designs in Economics. Journal of Economic Literature 48: 281-355.

Lee, I-Min, Howard D. Sesso, and Ralph S. Paffenbarger. 1999. Physical Activity and Risk of Lung Cancer. International Journal of Epidemiology, 28(4): 620-625.

Li, Xiaoyan, Michael Hurd, and David S. Loughran. 2008. The Characteristics of Social Security Beneficiaries Who Claim Benefits at the Early Entitlement Age. AARP Public Policy Institute Research Report No. 2008-19. Washington, DC: AARP.

Matthews, Charles E., Stephanie M. George, Stephen C. Moore, et al. 2012. Amount of Time Spent in Sedentary Behaviors and Cause-specific Mortality in US Adults. American Journal of Clinical Nutrition, 95:437-445.

Neuman, Kevin. 2008. Quit Your Job and Get Healthier? The Effect of Retirement on Health. Journal of Labor Research, 29(2): 177-201.

Olson, Janice. A. 1999. Who is “62 Enough”? Identifying Respondents Eligible for Social Security Benefits in the Health and Retirement Study. Social Security Bulletin, 62(3): 51-56.

Pantell, Matthew, David Rehkopf, Douglas Jutte, et al. 2013. Social Isolation: A Predictor of Mortality Comparable to Traditional Clinical Risk Factors. American Journal of Public Health, 103(11): 2056-2062.

Rust, John, and Christopher Phelan. 1997. How Social Security and Medicare affect Retirement Behavior in a World of Incomplete Markets. Econometrica, 65(4): 781-831.

Sickles, Robin, and Paul Taubman. 1997. Mortality and Morbidity among Adults and the Elderly. In Rosenzweig, Mark R., and Oded Stark (Eds.) Handbook of Population and Family Economics. Amsterdam, Netherlands, Elsevier Science Publishers, 1997. 559643.

Snyder, Stephen E., and William N. Evans. 2006. The Effect of Income on Mortality: Evidence from the Social Security Notch. Review of Economics and Statistics, 88(3): 482-495.

Social Security Administration. 2012. Annual Statistical Supplement to the Social Security Bulletin, 2011. Washington DC: SSA Office of Retirement and Disability Policy.

Solon, Gary, Steven J. Haider, and Jeffrey M. Wooldridge. 2015. What are we Weighting For? Journal of Human Resources, 50(2): 301-316.

Song, Jae, and Joyce Manchester. 2007. Have People Delayed Claiming Social Security Benefits? Responses to Changes in Social Security Rules. Social Security Bulletin, 67(2): 1-23.

Sorlie, Paul D., and Norman J. Johnson. 1996. Validity of Education Information on the Death Certificate. Epidemiology, 7: 437-439. 
Sorlie, Paul D., Eugene Rogot, and Norman J. Johnson. 1992. Validity of Demographic Characteristics on the Death Certificate. Epidemiology, 3(2): 181-184.

Sullivan, Daniel, and Till von Wachter. 2009. Job Displacement and Mortality: An Analysis Using Administrative Data. Quarterly Journal of Economics, 124(3): 1265-1306.

U.S. General Accountability Office. 2013. Social Security Death Data: Additional Action Needed to Address Data Errors and Federal Agency Access, GAO-14-16. Washington DC: US GAO.

Waschki, Benjamin, Anne Kirsten, Olaf Holz, et al. 2011. Physical Activity Is the Strongest Predictor of All-Cause Mortality in Patients with COPD: A Prospective Cohort Study, Chest, 140(2): 331-342.

Young, Robert P., Raewyn J. Hopkins, Timothy Christmas, et al. 2009. COPD Prevalence is Increased in Lung Cancer, Independent of Age, Sex and Smoking History. European Respiratory Journal, 34:380-386. 
Figure 1. Cumulative Rate for Ever Having Claimed Social Security, by Sex

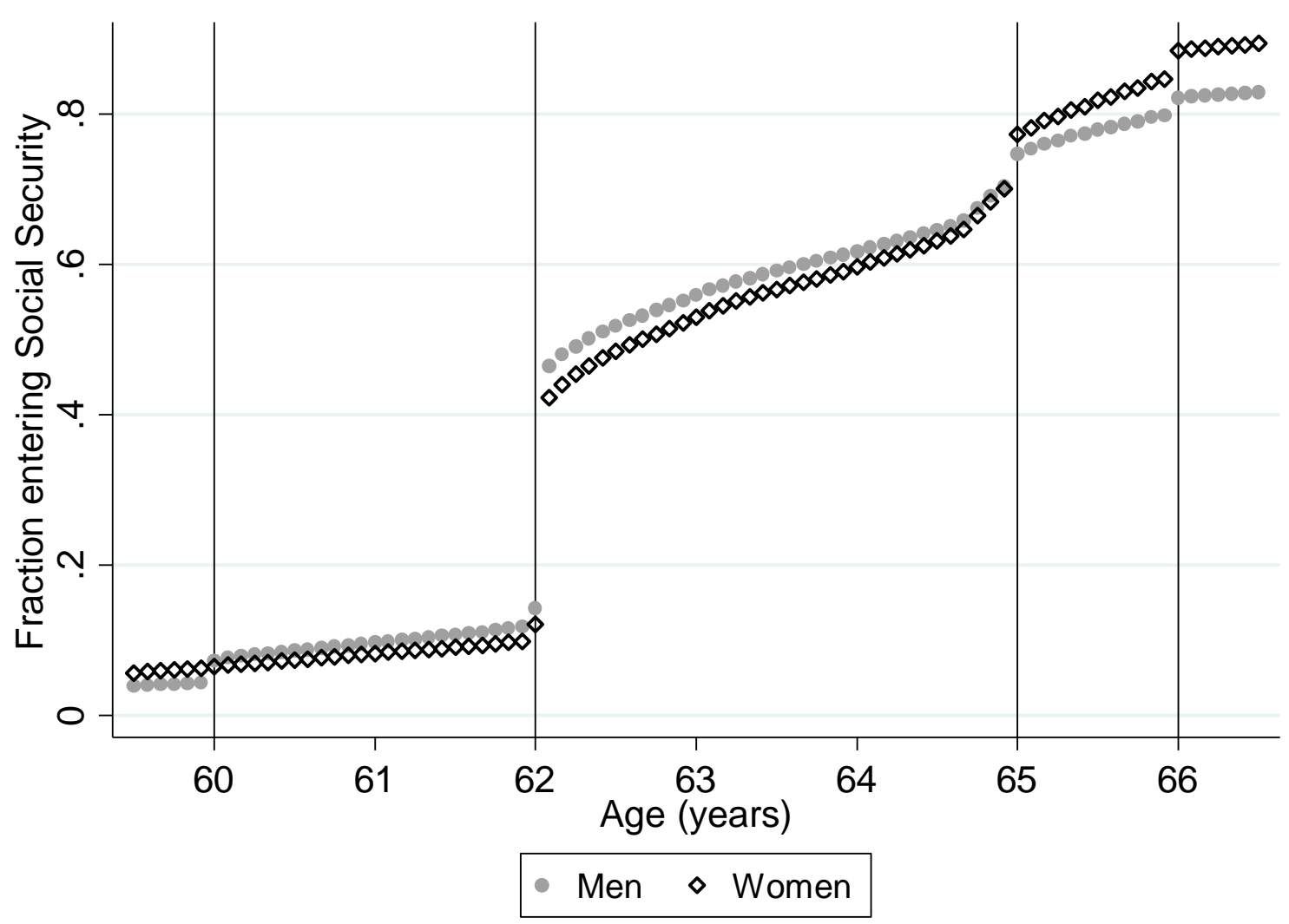

Notes: We use birth cohorts from 1921 to 1948 and include claims by both workers and dependents for all components of Social Security (i.e., Disability, Retirement and Survivors Insurance). Claims data is from a one percent extract of SSA's Master Beneficiary Record and Numident File. Claiming numbers are converted to rates based on population estimates from the Current Population Survey. 
Figure 2. Monthly Mortality Counts in Relation to Turning Age 62, Cohorts Born 1921-1948

A: All

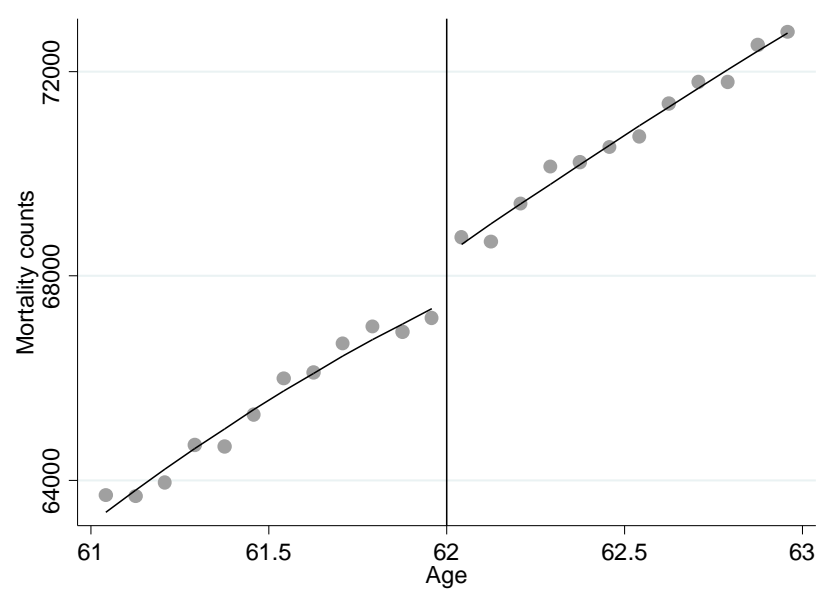

B: Males

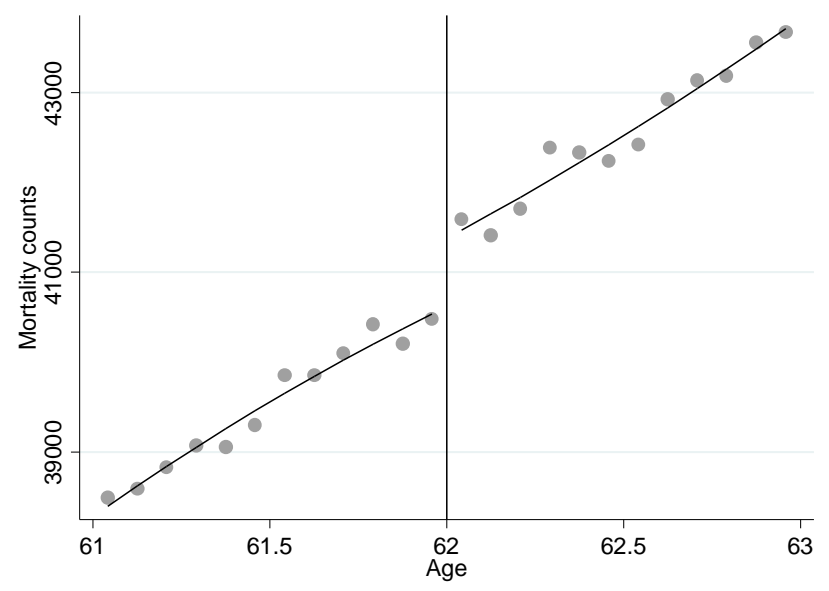

C: Females

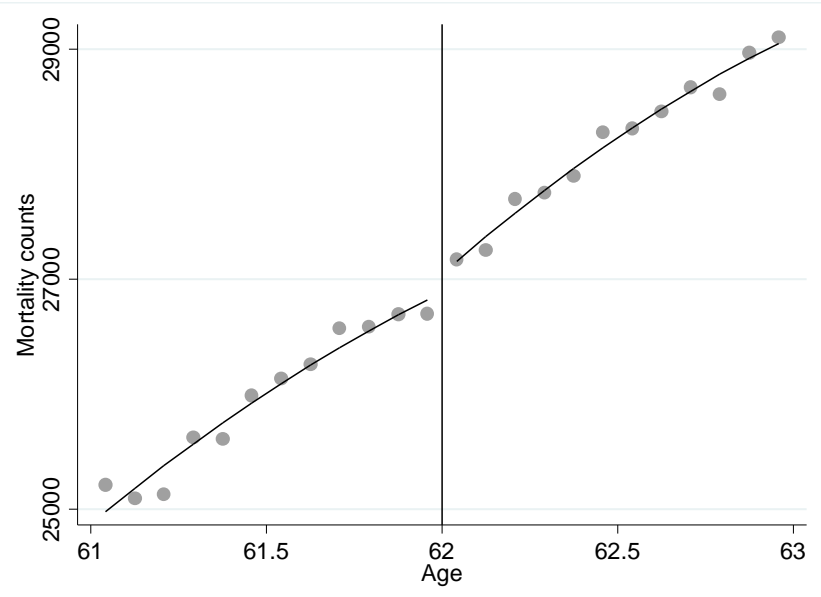

Notes: Data is from restricted-use versions of the Multiple Cause of Death data held at the National Center for Health Statistics. Reported mortality counts are for cohorts born from 1921 to 1948 . The figures show the number of deaths by age measured in months. 
Figure 3. The Distribution of Placebo Male Mortality Estimates for +/-60 Months of Age 62 Compared to the Estimate at Age 62 (Diamond, labeled)

\section{A: Local linear specification using CCT-calculated bandwidths}

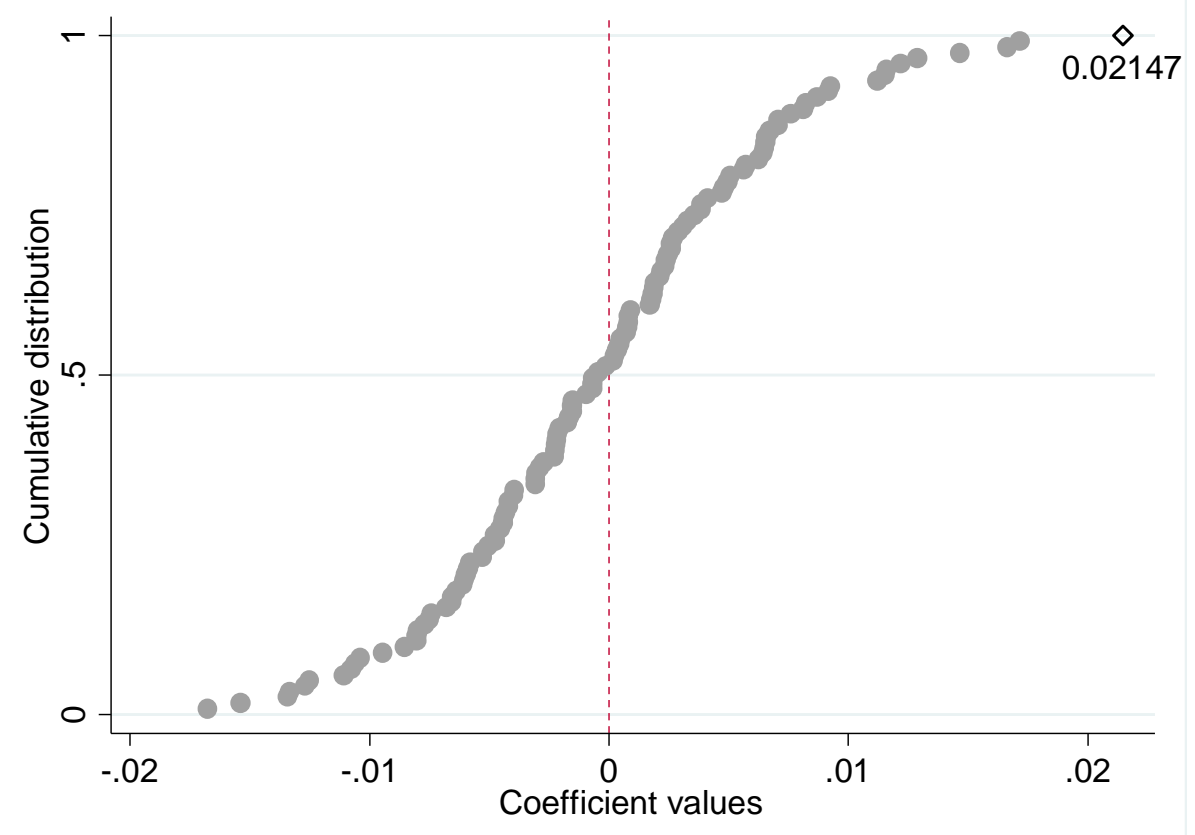

B: Global quadratic specification using a bandwidth of 12 months

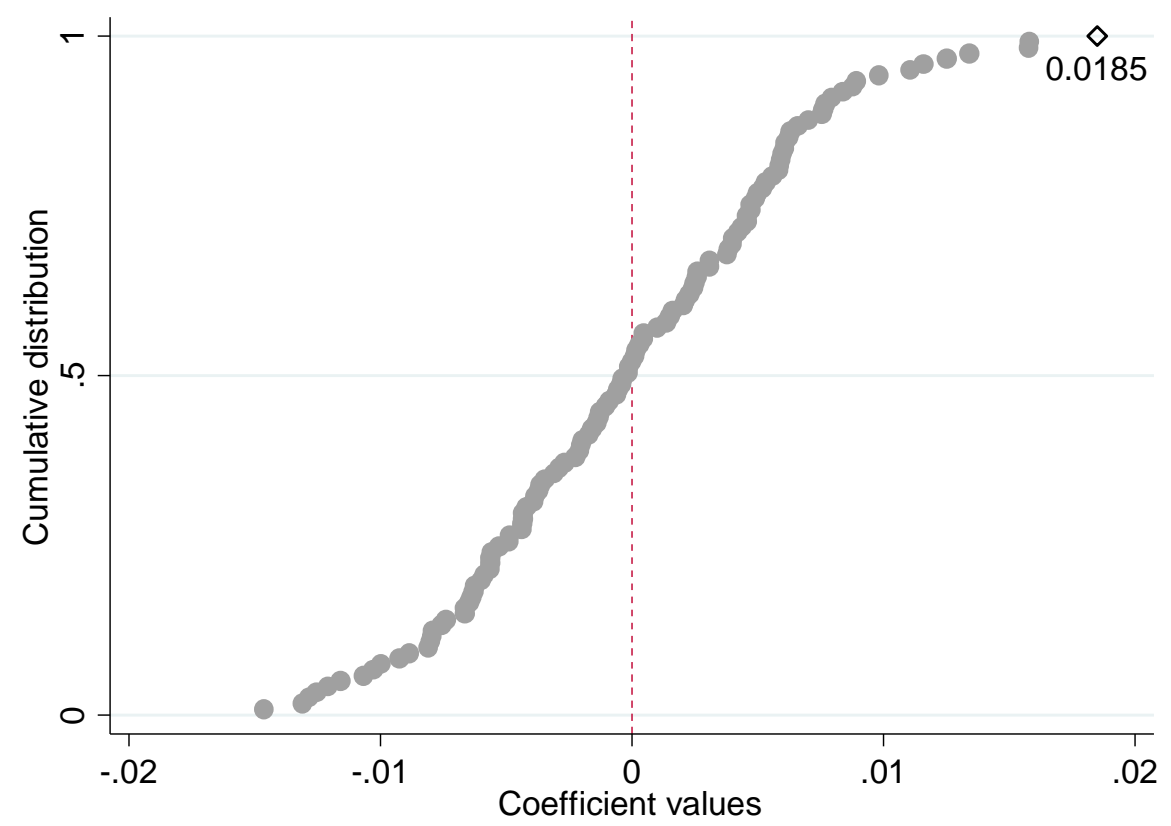

Notes: Data is from restricted-use versions of the Multiple Cause of Death data held at the National Center for Health Statistics, and includes the 1921 to 1948 cohorts. The figures show the conditional density functions of point estimates using each month $+/-60$ months before and after age 62 as placebos. The diamond represents the regression discontinuity estimate at age 62. CCT represents the bandwidth procedure of Calonico, Cattaneo and Titiunik (2014a; 2014b). See Table 2 and the text for more details. 
Figure 4. Changes in Social Security Claiming and Related Outcomes at Age 62

A: Males - Fraction entering Social Security

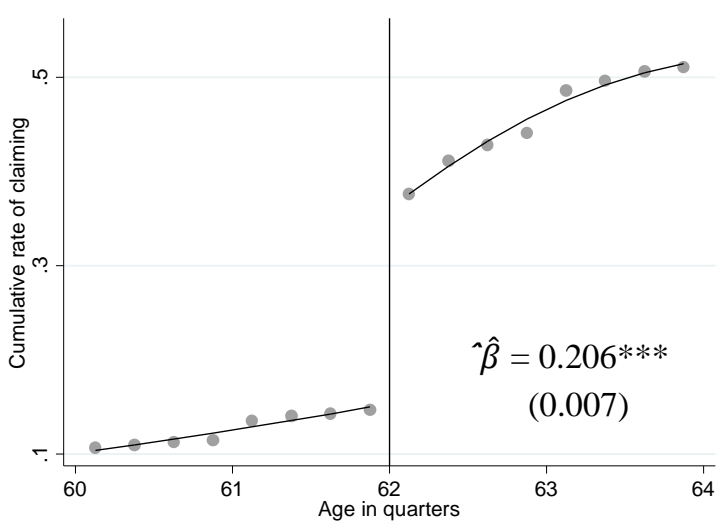

C: Males - Fraction retired

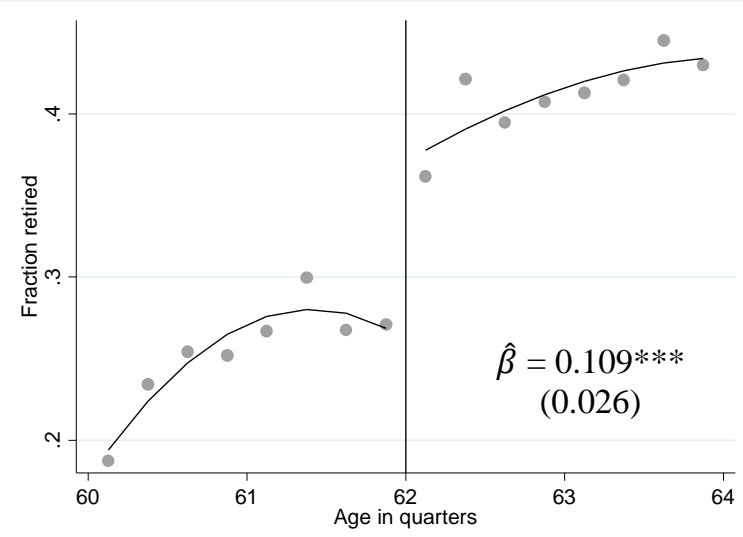

E: Males - Fraction in labor force

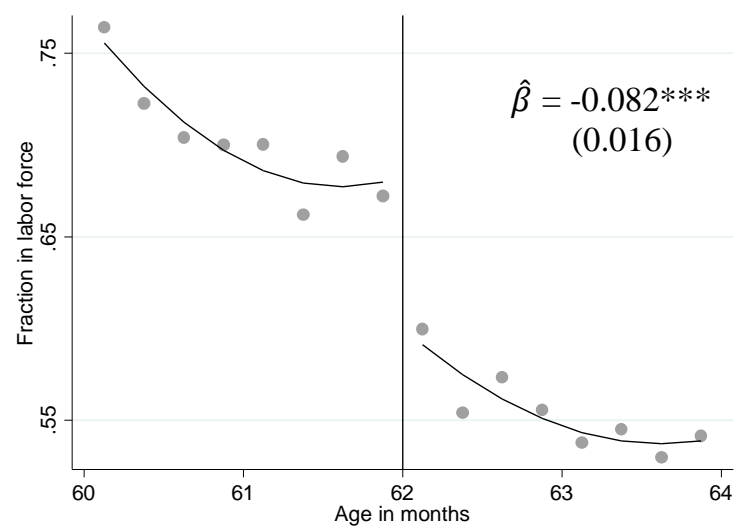

B: Females - Fraction entering Social Security

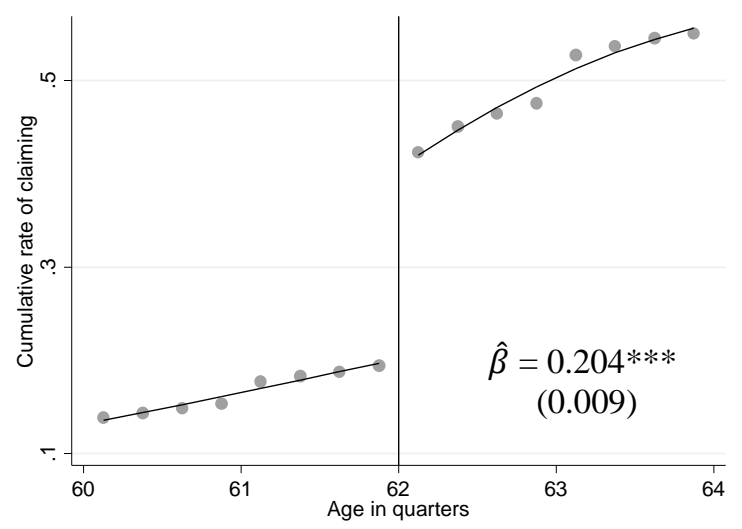

D: Females - Fraction retired

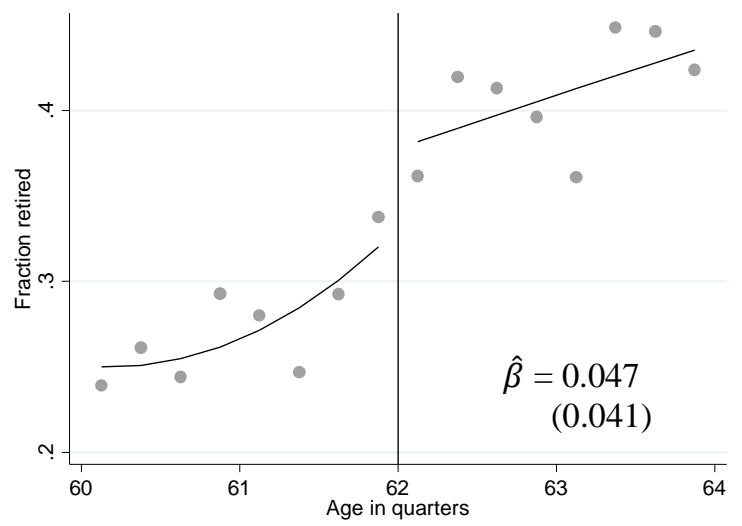

F: Females - Fraction in labor force

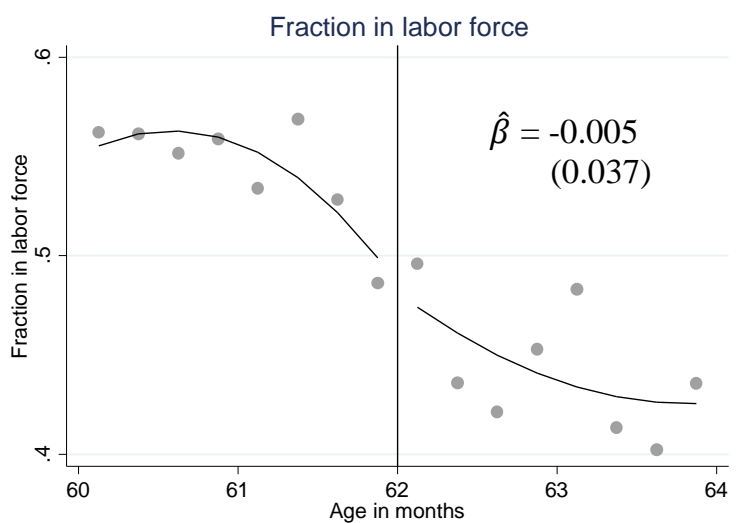


Figure 4. Changes in Social Security Claiming and Related Outcomes at Age 62 (Continued)

G: Males - Fraction working for pay

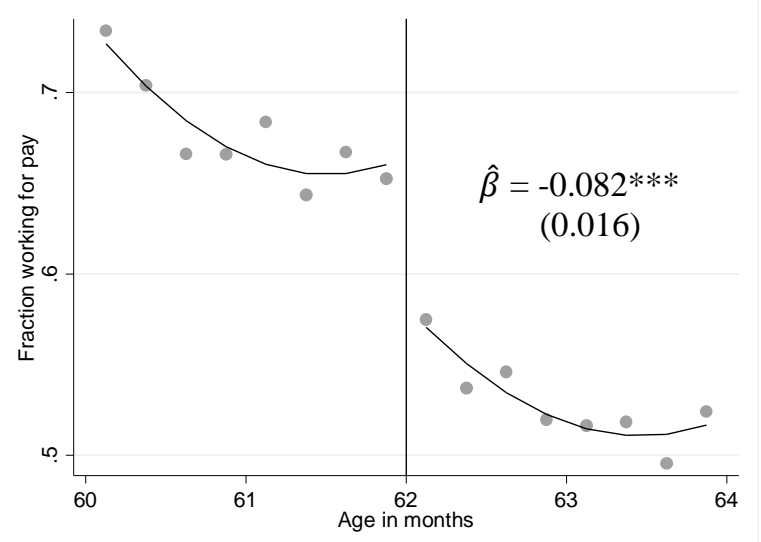

I: Males - Fraction with health insurance

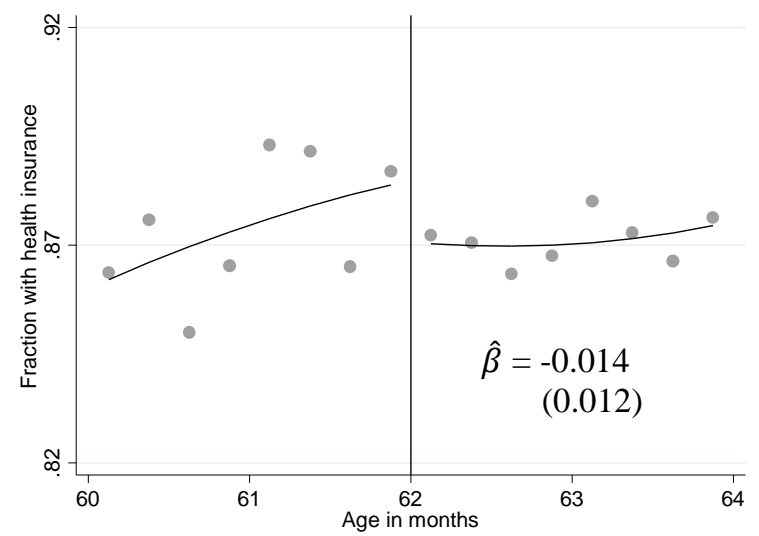

K: Males - Ave. household income (2014\$)

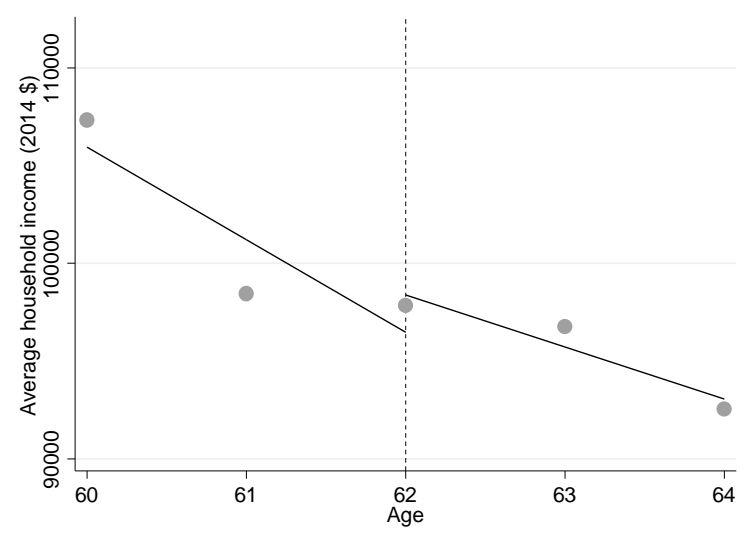

H: Females - Fraction working for pay

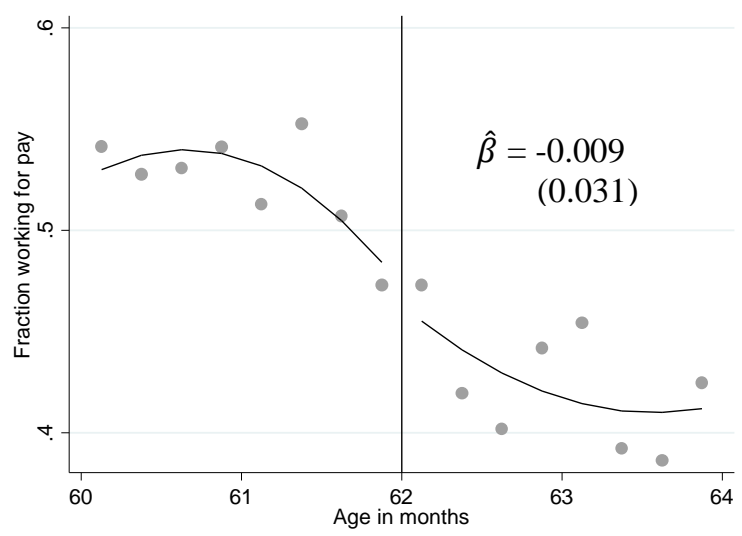

J: Females - Fraction with health insurance

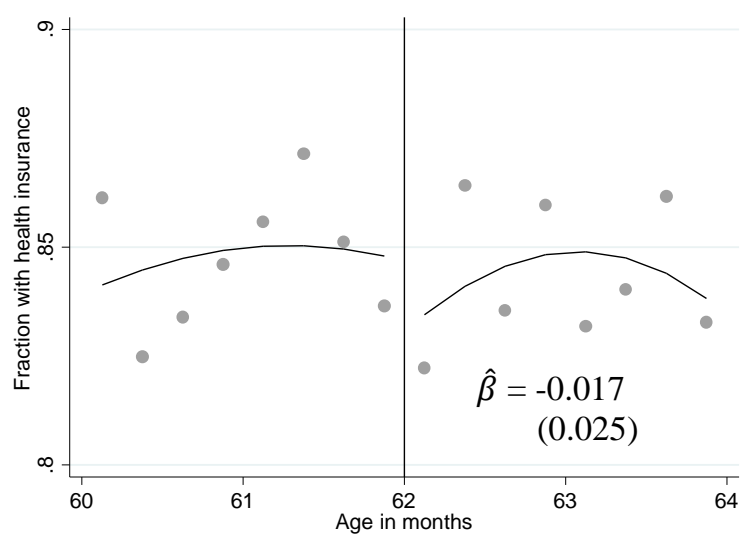

L: Females - Ave. household income (2014

\$)

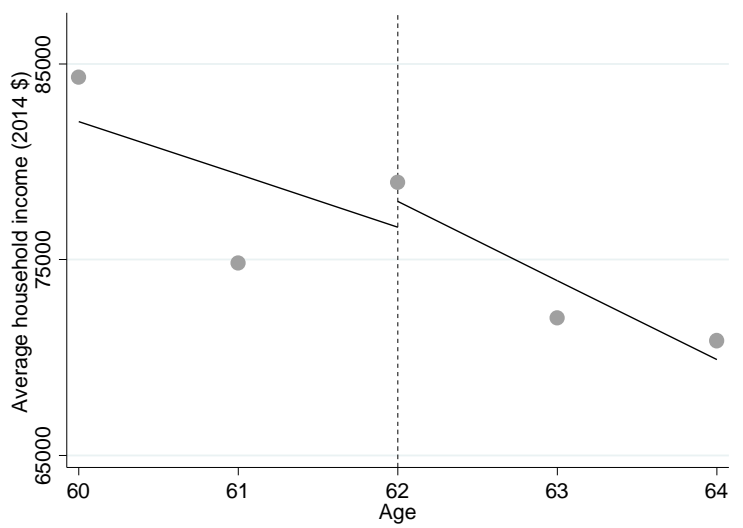

Notes: Data are from the RAND Health and Retirement Study Data File (Version N). The variables are described in the appendix. Average household income is shifted back one year, as HRS respondents are asked about income in the previous year (e.g., the income response when interviewed at age 63 is assigned as age 62 income). Income is converted to 2014 dollars using the CPI-U. 
Figure 5. The Relationship Between Changes in Mortality and Retirement Outcomes at Age 62

A: Started to claim Social Security

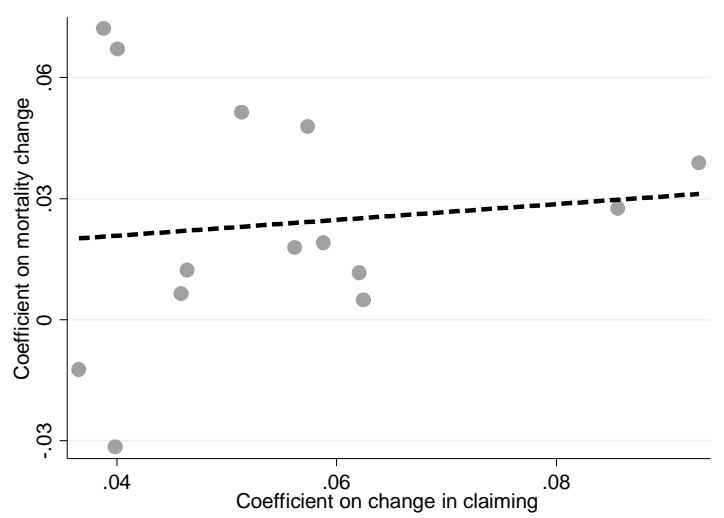

C: In labor force

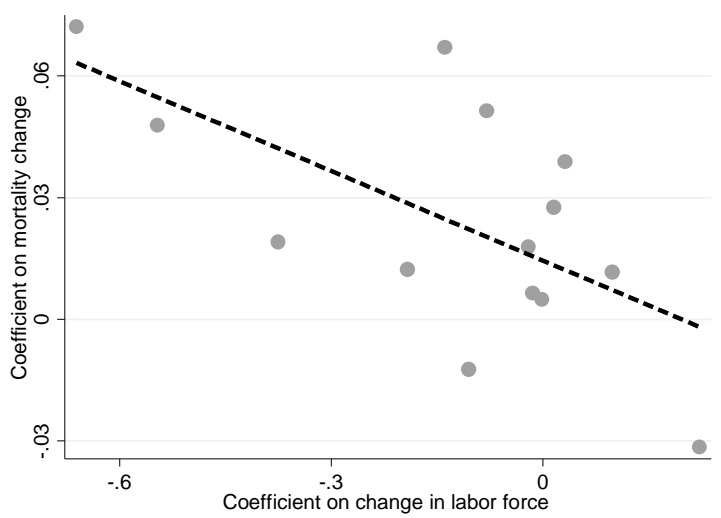

E: Has health insurance

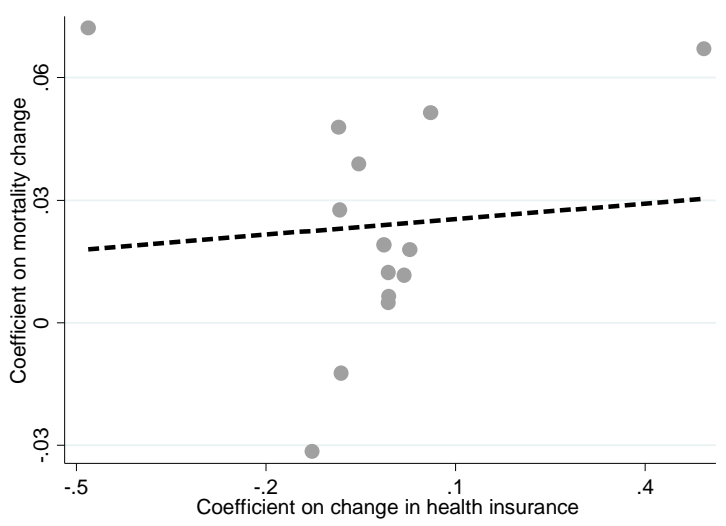

B: Retired

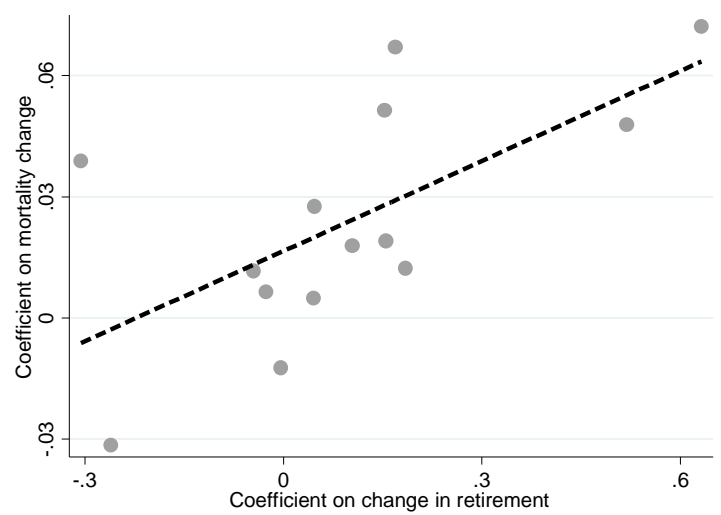

D: Currently working for pay

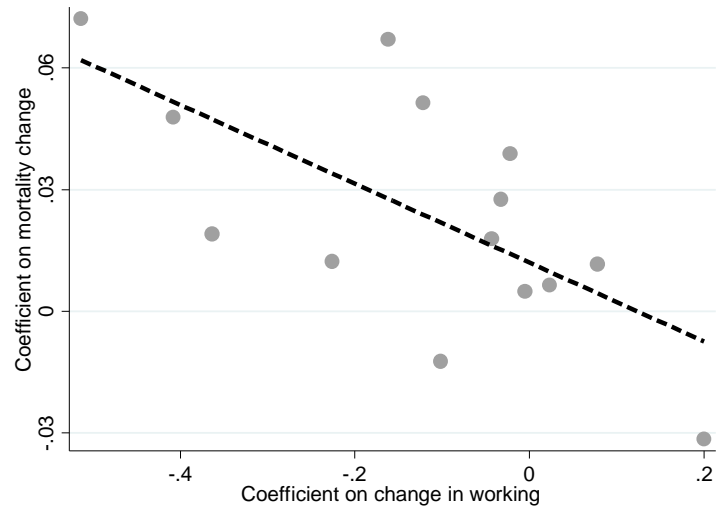

F: Average household income (2014 \$)

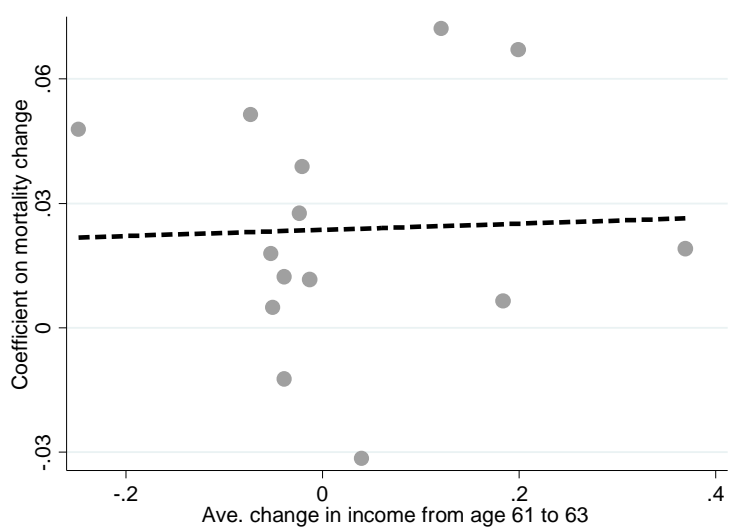

Notes: These coefficients come from the global quadratic RD regression. Each panel shows the mortality coefficients plotted for 14 distinct demographic subgroups in relation to the horizontal axis and the estimated changes in the retirement-related outcomes for the same 14 groups plotted in relation to the vertical axis. For the non-mortality outcomes, we use data from the RAND Health and Retirement Study Data File (Version N); these variables are described in the appendix. Average household income is shifted back one year, as HRS respondents are asked about income in the previous year (e.g., the income response when interviewed at age 63 is assigned as age 62 income). Income is converted to 2014 dollars using the CPI-U. 
Table 1. Summary Statistics, Multiple Cause of Death Data

\begin{tabular}{|c|c|c|c|c|c|c|}
\hline & \multicolumn{2}{|c|}{ All } & \multicolumn{2}{|c|}{ Males } & \multicolumn{2}{|c|}{ Females } \\
\hline & Age 61 & Age 62 & Age 61 & Age 62 & Age 61 & Age62 \\
\hline Total deaths & 785,871 & 848,728 & 474,272 & 510,561 & 311,599 & 338,167 \\
\hline Ave. deaths per month & 65,489 & 70,727 & 39,523 & 42,547 & 25,967 & 28,181 \\
\hline \multicolumn{7}{|l|}{ Race } \\
\hline White (\%) & 82.7 & 82.8 & 83.4 & 83.5 & 81.6 & 81.7 \\
\hline Black (\%) & 15.3 & 15.1 & 14.7 & 14.5 & 16.2 & 16.1 \\
\hline Other race (\%) & 2.0 & 2.1 & 1.9 & 2.0 & 2.2 & 2.2 \\
\hline \multicolumn{7}{|l|}{ Marital Status } \\
\hline Single (\%) & 9.0 & 8.9 & 10.0 & 9.8 & 7.5 & 7.5 \\
\hline Married (\%) & 60.2 & 59.5 & 65.2 & 65.0 & 52.5 & 51.3 \\
\hline Divorced (\%) & 18.7 & 18.6 & 18.9 & 18.8 & 18.5 & 18.4 \\
\hline Widowed (\%) & 12.1 & 13.0 & 5.9 & 6.4 & 21.4 & 22.9 \\
\hline \multicolumn{7}{|l|}{ Educational Attainment } \\
\hline Less than high school (\%) & 26.4 & 26.8 & 27.4 & 27.6 & 25.1 & 25.6 \\
\hline High school graduate (\%) & 59.3 & 59.0 & 56.7 & 56.5 & 63.1 & 62.8 \\
\hline College graduate (\%) & 14.3 & 14.2 & 16.0 & 15.9 & 11.8 & 11.7 \\
\hline \multicolumn{7}{|l|}{ Place of Death } \\
\hline Hospital (\%) & 59.3 & 58.6 & 59.3 & 58.6 & 59.4 & 58.6 \\
\hline Nursing home/institution (\%) & 6.8 & 7.4 & 6.0 & 6.5 & 8.0 & 8.7 \\
\hline Residence or other location (\%) & 33.9 & 34.1 & 34.8 & 35.0 & 32.6 & 32.7 \\
\hline \multicolumn{7}{|l|}{ Underlying Cause of Death } \\
\hline Cancer (\%) & 36.7 & 36.6 & 33.5 & 33.7 & 41.4 & 40.7 \\
\hline $\begin{array}{l}\text { Cardiovascular and respiratory } \\
\text { conditions (\%) }\end{array}$ & 36.2 & 36.5 & 39.2 & 39.1 & 31.7 & 32.3 \\
\hline External causes (\%) & 4.5 & 4.1 & 5.3 & 4.8 & 3.3 & 3.1 \\
\hline All other causes (\%) & 22.7 & 22.9 & 22.0 & 22.2 & 23.6 & 24.0 \\
\hline
\end{tabular}

Notes: Data is from restricted-use versions of the Multiple Cause of Death data held at the National Center for Health Statistics, including the 1921 to 1948 cohorts. The sample includes all deaths for cohorts born between 1921 and 1948 . Marital status is missing in 0.9 percent of cases and place of death is missing in 0.7 percent of cases. As educational attainment is only available after 1989, it is available for 69.1 percent of all cases. The category "Residence or other location” includes those classified as "Dead on arrival” at the hospital. 
Table 2. Regression Estimates of Increase in Mortality at Age 62

\begin{tabular}{lccc}
\hline \hline Regression type & All & Males & Females \\
& $(1)$ & $(2)$ & $(3)$ \\
\hline Global parametric regressions (bandwidth $=12$ months) & & & \\
Quadratic regression & $0.0135^{* * *}$ & $0.0185^{* * *}$ & 0.0058 \\
& $(0.0043)$ & $(0.0049)$ & $(0.0049)$ \\
Cubic regression & $0.0197^{* * *}$ & $0.0236^{* * *}$ & $0.0138^{* * *}$ \\
& $(0.0049)$ & $(0.0060)$ & $(0.0047)$ \\
Quartic regression & $0.0193^{* * *}$ & $0.0243^{* * *}$ & $0.0116^{* * *}$ \\
& $(0.0051)$ & $(0.0082)$ & $(0.0043)$ \\
Local nonparametric regressions & & & \\
Local linear using data-driven bandwidth & $0.0142^{* * *}$ & $0.0215^{* * *}$ & $0.0103^{* * *}$ \\
& $(0.0036)$ & $(0.0041)$ & $(0.0030)$ \\
Data-driven bandwidth & 10 months & 7 months & 6 months \\
Local quadratic using data-driven bandwidth & $0.0194^{* * *}$ & $0.0233^{* * *}$ & $0.0131^{* * *}$ \\
Data-driven bandwidth & $(0.0039)$ & $(0.0058)$ & $(0.0026)$ \\
\hline \hline
\end{tabular}

Notes: $* *$ denotes $\mathrm{p}<0.05, * * *$ denotes $\mathrm{p}<0.01$. Data is from restricted-use versions of the Multiple Cause of Death data, including the 1921 to 1948 cohorts. The global parametric regressions allow for the polynomial to vary either side of the discontinuity and we report robust standard errors. The nonparametric regressions are estimated using the "robust data-driven" procedures of Calonico, Cattaneo and Titiunik (2014a; 2014b). We use a triangular kernel, robust standard errors, and their bandwidth selection and bias correction procedures. See text for more details.

Table 3. Estimated Change in Mortality at Age 62, Male Subgroups

\begin{tabular}{|c|c|c|c|c|c|c|c|}
\hline & $\begin{array}{c}\text { Local } \\
\text { linear } \\
(1) \\
\end{array}$ & $\begin{array}{c}\text { Global } \\
\text { quadratic } \\
(2)\end{array}$ & $\begin{array}{c}\text { Fraction } \\
\text { of deaths } \\
(3)\end{array}$ & & $\begin{array}{c}\text { Local } \\
\text { linear } \\
(4) \\
\end{array}$ & $\begin{array}{c}\text { Global } \\
\text { quadratic } \\
(5)\end{array}$ & $\begin{array}{c}\text { Fraction } \\
\text { deaths } \\
(6)\end{array}$ \\
\hline Marital status & & & & Education & & & \\
\hline Married & $\begin{array}{c}0.0130 * * \\
(0.0058)\end{array}$ & $\begin{array}{c}0.0081 \\
(0.0057)\end{array}$ & $65.1 \%$ & $\begin{array}{l}\text { Did not complete } \\
\text { high school }\end{array}$ & $\begin{array}{r}0.0303^{* *} \\
(0.0103)\end{array}$ & $* \begin{array}{r}0.0275 * * \\
(0.0115)\end{array}$ & $27.6 \%$ \\
\hline Not married & $\begin{array}{c}0.0415^{* * *} \\
(0.0079)\end{array}$ & $\begin{array}{r}0.0377 * * * \\
(0.0107)\end{array}$ & $34.9 \%$ & $\begin{array}{l}\text { Completed high } \\
\text { school, not college }\end{array}$ & $\begin{array}{c}0.0087 \\
(0.0050)\end{array}$ & $\begin{array}{c}0.0099 \\
(0.0066)\end{array}$ & $56.5 \%$ \\
\hline - Single & $\begin{array}{c}0.0558 * * * \\
(0.0056)\end{array}$ & $\begin{array}{c}0.0514^{* * *} \\
(0.0111)\end{array}$ & $9.9 \%$ & Completed college & $\begin{array}{c}0.0146 \\
(0.0146)\end{array}$ & $\begin{array}{c}0.0187 \\
(0.0181)\end{array}$ & $15.9 \%$ \\
\hline - Divorced & $0.0305 * * *$ & $0.0337 * *$ & $18.9 \%$ & & & & \\
\hline & $(0.0111)$ & $(0.0137)$ & & \multicolumn{4}{|l|}{$\overline{\text { Place of death }}$} \\
\hline - Widowed & $\begin{array}{l}0.0330 \\
(0.0202)\end{array}$ & $\begin{array}{c}0.0262 \\
(0.0248)\end{array}$ & $6.2 \%$ & \multicolumn{3}{|c|}{$\begin{array}{ccc}\text { Out of hospital/ in- } & 0.0339 * * * & 0.0323 * * * \\
\text { stitution } & (0.0074) & (0.0073)\end{array}$} & $34.6 \%$ \\
\hline$\frac{\text { Race }}{\text { White }}$ & $0.0237 * * *$ & $0.0209 * * *$ & $83.5 \%$ & In hospital & $\begin{array}{c}0.0124 \\
(0.0064)\end{array}$ & $\begin{array}{c}0.0130 \\
(0.0070)\end{array}$ & $58.5 \%$ \\
\hline Non-white & $\begin{array}{c}(0.0042) \\
0.0078 \\
(0.0104)\end{array}$ & $\begin{array}{c}(0.0053) \\
0.0068 \\
(0.0115) \\
\end{array}$ & $16.5 \%$ & $\begin{array}{l}\text { In nursing home/ } \\
\text { institution }\end{array}$ & $\begin{array}{l}-0.0022 \\
(0.0161)\end{array}$ & $\begin{array}{l}-0.0079 \\
(0.0194)\end{array}$ & $6.2 \%$ \\
\hline
\end{tabular}

Notes: ** denotes $\mathrm{p}<0.05$, *** denotes $\mathrm{p}<0.01$. We show coefficients and standard errors for local linear (using bandwidths selected using the procedures of Calonico, Cattaneo, Titiunik (2014a; 2014b)) and global quadratic regressions (using a 12-month bandwidth). Fraction of deaths is for male deaths at age 61 and 62. See Table 2 and the text for more details. 


\section{Data Appendix}

\section{A1. Cause of Death Categories in the MCOD Files}

The MCOD files are explained in Section 3. Here we provide more details about how we create consistent cause-of-death categories across the $9^{\text {th }}$ and $10^{\text {th }}$ Versions of the International Classification of Disease (ICD-9 and ICD-10). We use the classification of Evans and Moore (2012) that was developed using epidemiological studies and cause-of-death recodes. For underlying cause of death, there is a 34-cause recode for ICD-9 (“Recode34”) and a 39-cause recode for ICD-10 (“Recode39”). Underlying causes of death are categorized as follows:

- Heart and lung conditions: Heart attacks (ICD-9: 410; ICD-10: I21); COPD (ICD-9: 490496; ICD-10: J40-J43, J44.0-J44.7, J44.9, J45-J48); Other heart and lung conditions (ICD-9: 390-398, 402, 404, 411-439; ICD-10: I00-I09, I11, I13, I20, I22-I51, I60-I69);

- Cancers: Lung cancer (ICD-9: 162.2-162.5, 162.8-162.9; ICD-10: C34); Other cancers (ICD-9: Recode34 = 4, 5, 8, 9 or 11 and not assigned to lung cancer; ICD-10: Recode39 =4-7, $10-13$ or 15 and not assigned to lung cancer);

- $\quad$ External causes: Traffic fatalities (ICD-9: Recode34 = 33, Recode39 = 38); Other external causes (ICD-9: Recode34 = 34-36, Recode39 = 39-41).

All other causes of death are included in the other category. This accounts for approximately 22 percent of all deaths during the sample period.

\section{A2. Social Security Administrative Data Extract}

We use two datasets drawn from SSA program management systems. The Master Beneficiary Record is used to manage Social Security activity. The Numident File contains vital statistics information for the entire population and is used to manage Social Security Numbers. We use a one percent extract of these datasets that are based on the last two digits of Social Security Numbers, which are essentially randomly assigned.

We focus on the first date that a beneficiary is eligible to receive Social Security and whether the claim is made on their own record (i.e., as a worker beneficiary) or someone else's record (i.e., as a dependent). Date of birth is used to calculate the age of claiming, and year of birth is used to restrict the sample to those born between 1921 and 1948 (the same sample available in the MCOD Files). We combine claiming for Disability Insurance or Retirement and Survivors’ Insurance in our figures, as individuals can apply for both simultaneously and commonly 
transition from one program to another. However, we do confirm that the spike at 62 is due to Retirement and Survivors’ Insurance claims.

To convert this information into rates, we use monthly extracts of the Current Population Survey to calculate the sex- and age-specific population numbers for these cohorts. While we could use mortality information from the Numident File to calculate these numbers, we use survey estimates as a review by the Social Security Administration Office of the Inspector General (2012) suggests that the Numident mortality numbers are subject to measurement error.

\section{A3. Health and Retirement Study (HRS) Data}

The HRS provides comprehensive information on Americans in households aged 50 and older, including their demographic characteristics, employment, retirement plans, income sources, health insurance and health outcomes. It began in 1992 with a nationally representative sample of individuals living in households who were born between 1931 and 1941, who have since been interviewed every two years. Older and younger cohorts have since been added and subsequently interviewed very two years. We use the RAND HRS File (Version N), which contains data through 2012 and cohorts born between 1924 and 1959 (Chien et al., 2014). In the RAND HRS File, variables are created that are internally consistent and consistent across waves.

Age at interview is calculated using date of birth and final date of interview, and respondent-specific sample weights are used throughout. The work-related variables are: retired (based on labor force status, where respondents defined as retired mention retirement and currently are not working and or looking for work); currently in labor force (using the variable that follows the Bureau of Labor Statistics definition); and working for pay (if respondent is currently working for pay). Household income and Social Security income are from the previous calendar year and converted to 2014 values using the CPI-U. For these variables, age is calculated for the previous year (i.e., the year the income was earned). The health insurance variables are: has health insurance coverage (if has government health insurance or a health insurance plan); and the number of health insurance plans a respondent reports.

For these variables, we aggregate the different waves and use the fraction of respondents or average response at each age of interview. In the two years before age 62 (i.e., age 60 to 63), we have a sample of 12,632 males and 14,119 females. For Social Security claiming, age of first claiming is retrospective and does not vary across waves. We therefore use a slightly different sample that omits respondents who have not yet reached an age where they eligible for Social 
Security or who are less likely to accurately recall their exact claiming date. We use respondents whose highest age at interview is between 63 and 80. In this sample, we have a sample of 6,897 males and 7,462 females, with the smaller sample due to not having repeated observations from the same respondents.

\section{A4. National Health and Nutrition Examination Survey (NHANES) Data}

NHANES measures the health status of the American civilian population via both interviews and physical examinations. A subset of participants in the NHANES 2003/04 and 2005/06 cycles were asked to wear Actigraph accelerometers on their right hip for seven days during waking hours except when it could get wet (e.g., bathing). Data was recorded in one minute increments. By calibrating accelerometer readings to different activity levels, researchers have used these data to examine sedentary behavior and physical activity levels (e.g., Matthews et al, 2008; Healy et al, 2011).

We examine the fraction of time that participants were sedentary, and follow previous studies by defining being sedentary as whenever activity falls below 100 counts per minute. We focus on NHANES participants aged 60 to 63 years. We include them if they had data judged to be valid between $8 \mathrm{am}$ and $6 \mathrm{pm}$ on weekdays. This restriction matters because not all participants consistently wore their accelerometers. Following previous studies, we assume an accelerometer is being worn when there was at least two minutes of activity in an hour (Matthews et al., 2008; Troiano et al., 2008). Like these studies, we also exclude data where the device was found to be not calibrated (upon its return) or the data was classified by NHANES as unreliable. There are 179 observations (92 males, 87 females). For the ages that we are interested in, there are not marked differences in non-wear times by age.

We provide evidence that at age 62 there is an increase in the fraction of time that males are sedentary. It is difficult to link that directly to Social Security claiming, as the focus of the NHANES is on health-related outcomes. There is no information on whether people are receiving Social Security. Information about work and retirement is extremely limited, although the fraction of all respondents who are not working because of retirement does go up by 14 percentage points at age 62 . 


\section{Additional References}

Evans, William N., and Timothy J. Moore. 2012. Liquidity, Economic Activity, and Mortality. Review of Economics and Statistics, 94(2): 400-418.

Healy, Genevieve N., Charles N. Matthews CE, David W. Dunstan, et al. 2011. Sedentary Time and Cardio-metabolic Biomarkers in US Adults: NHANES 2003-06. European Heart Journal, 32(5): 590-597.

Matthews Charles E., Kong Y. Chen, Patty S. Freedson, et al. 2008. Amount of Time Spent in Sedentary Behaviors in the United States, 2003-2004. American Journal of Epidemiology, 167(7): 875-881.

Social Security Administration Office of the Inspector General. 2012. Title II Deceased Beneficiaries Who Do Not Have Death Information on the Numident. Audit Report A-09-112271. Social Security Administration Office of the Inspector General, Baltimore MD.

Troiano, Richard P., David Berrigan, Kevin W. Dodd, et al. 2008. Physical Activity in United States Measured by Accelerometer. Medicine and Science in Sports and Exercise, 40(1): 181-188. 


\section{Results Appendix}

Appendix Figure A1. Monthly Mortality Counts in Relation to Turning Age 61 and 63

A: All - Age 61

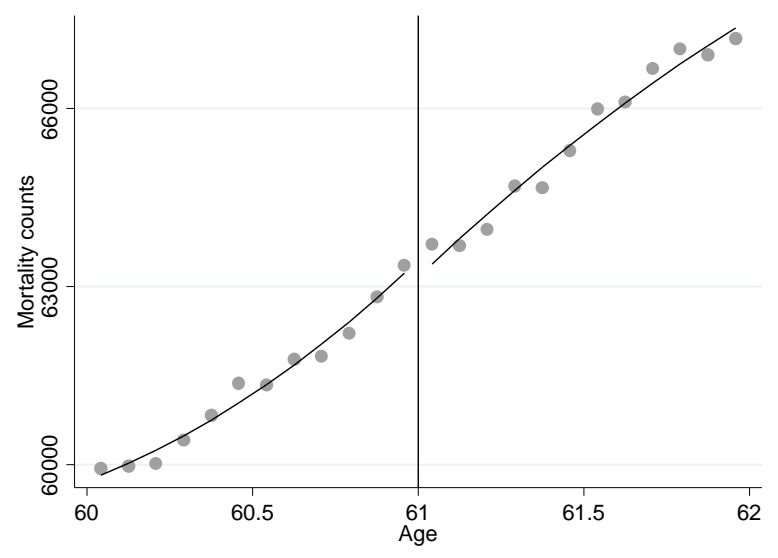

C: Males - Age 61

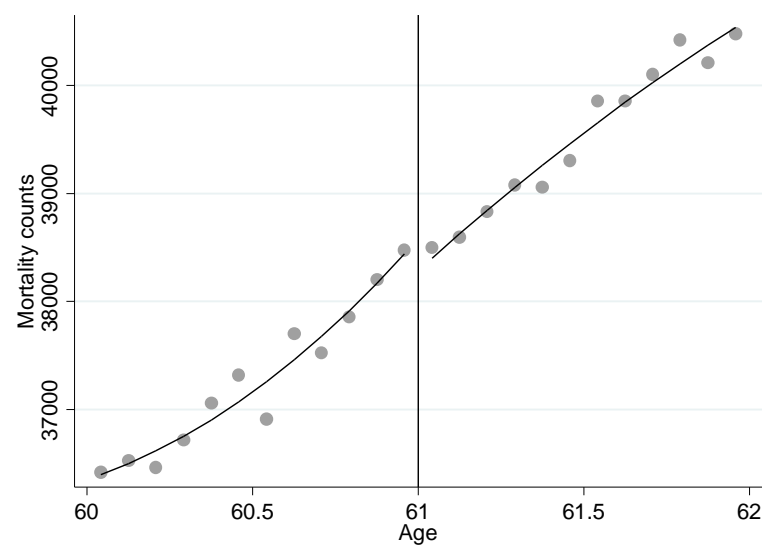

E: Females - Age 61

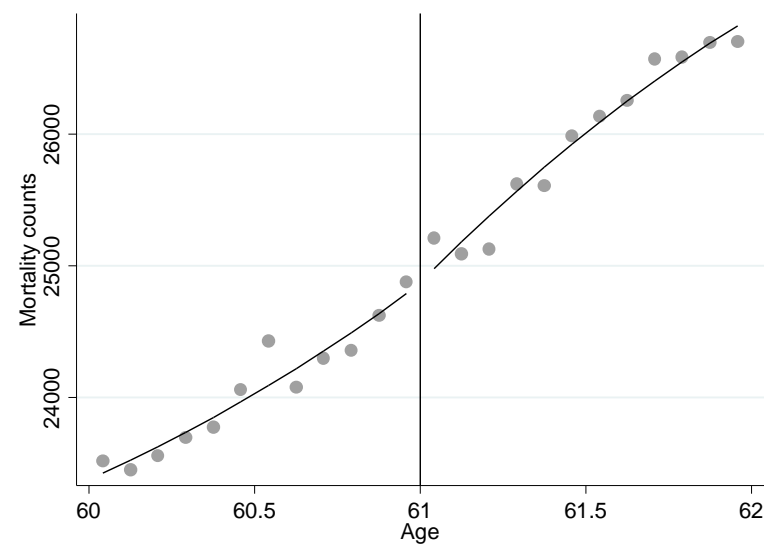

B: All - Age 63

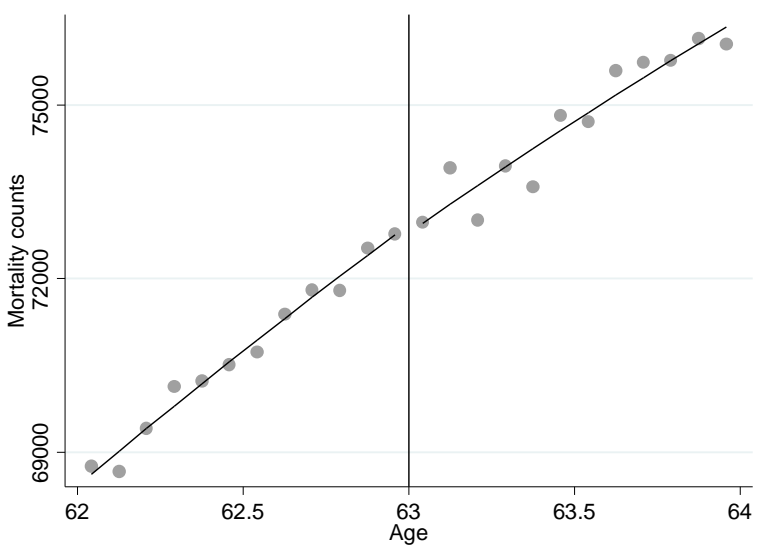

D: Males - Age 63

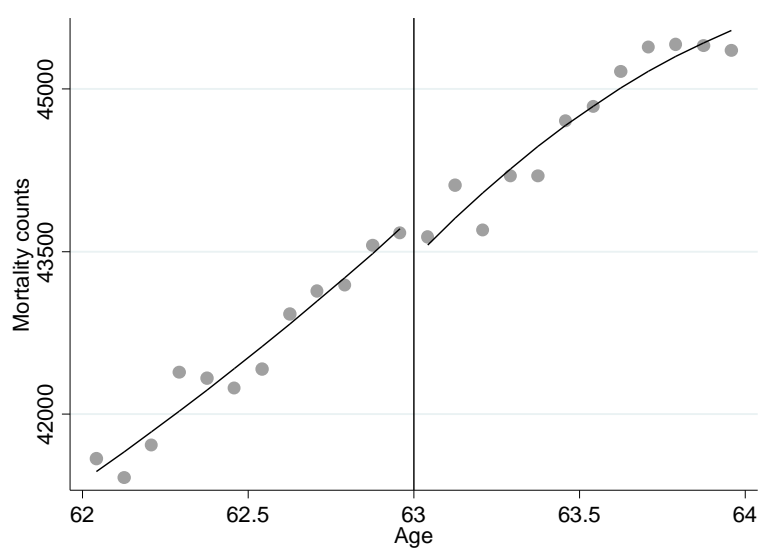

F: Females - Age 63

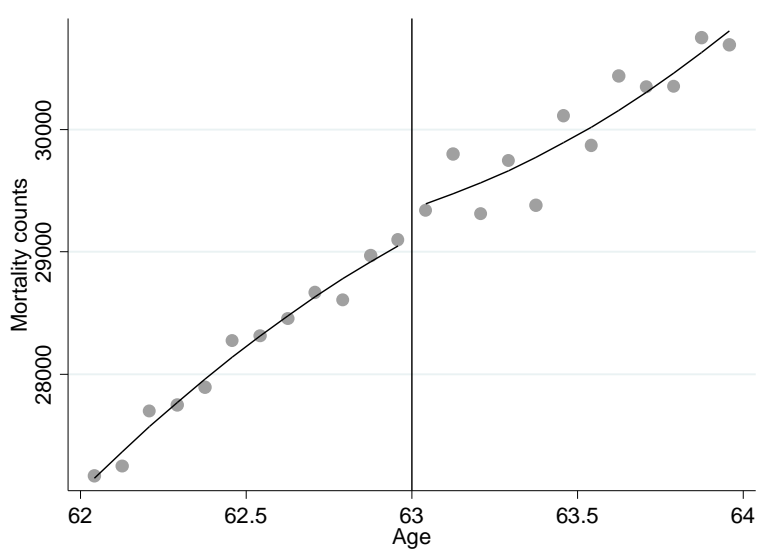

Notes: Data is from restricted-use versions of the Multiple Cause of Death data held at the National Center for Health Statistics. Reported mortality counts are for the 1921 to 1948 cohorts. The figures report the number of deaths by age measured in months. 


\section{Appendix Figure A2. Robustness of Estimates to Bandwidth}
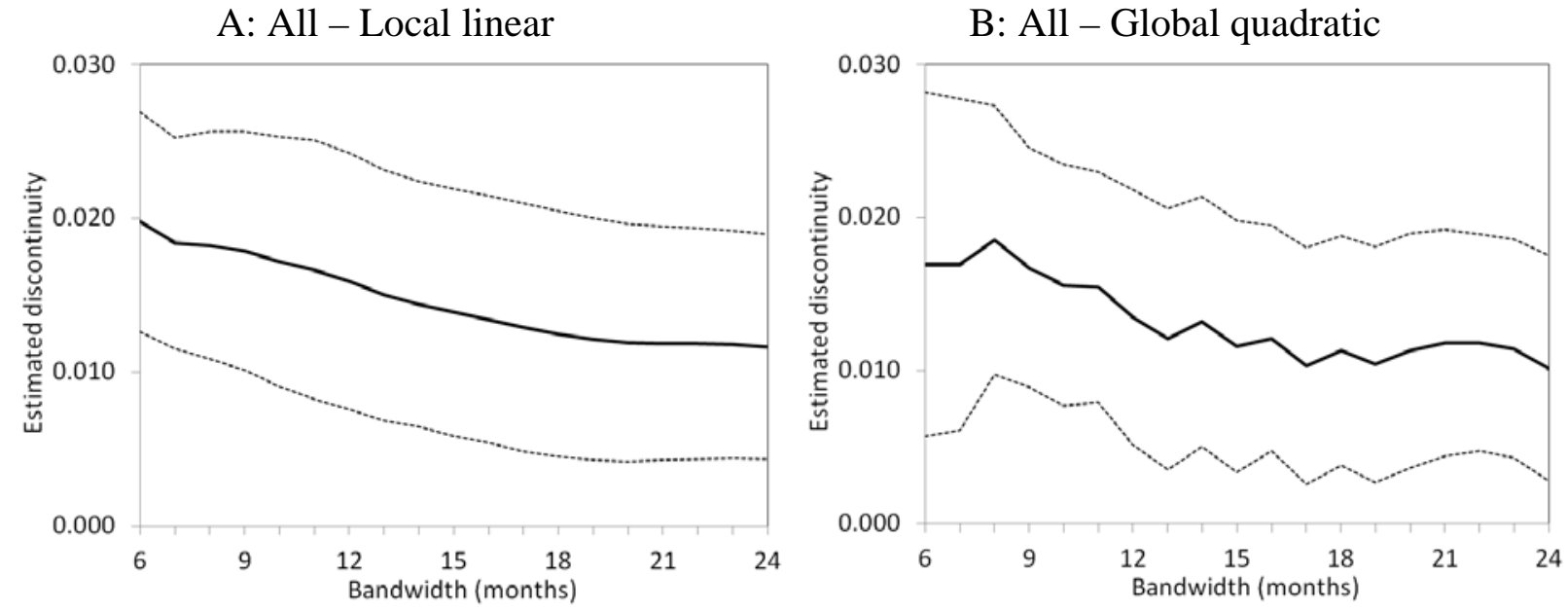

C: Males - Local linear
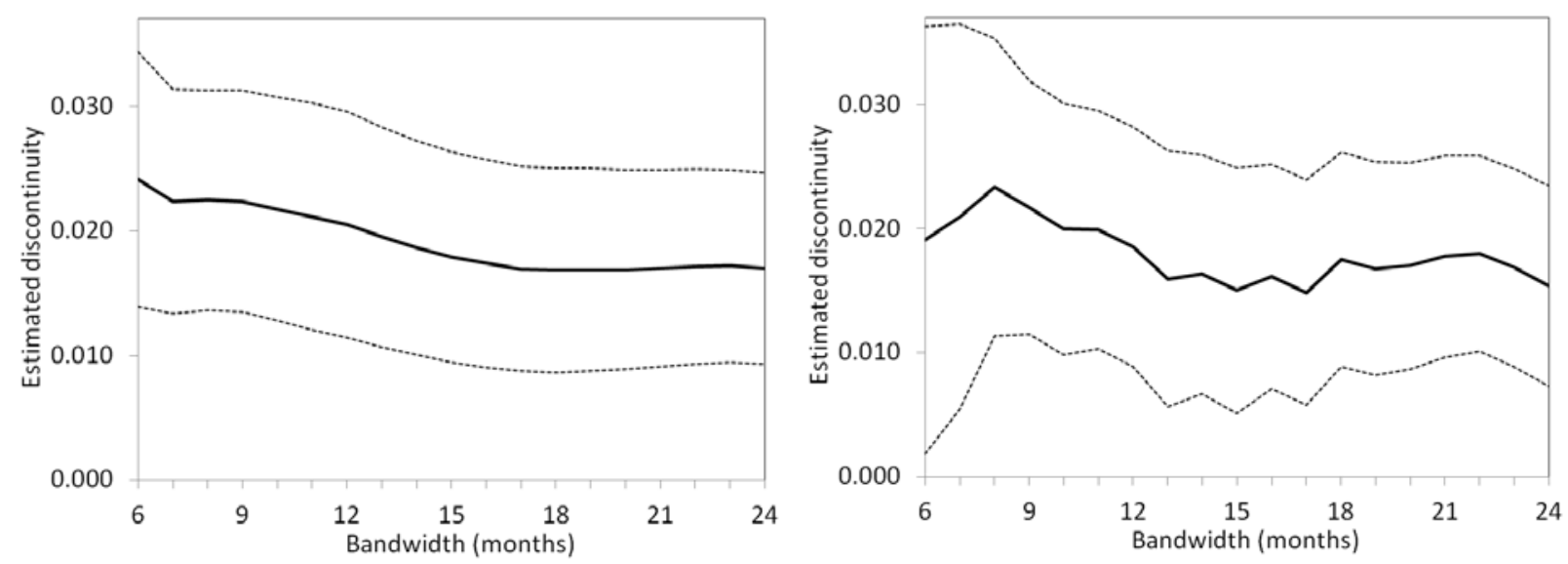

E: Females - Local linear

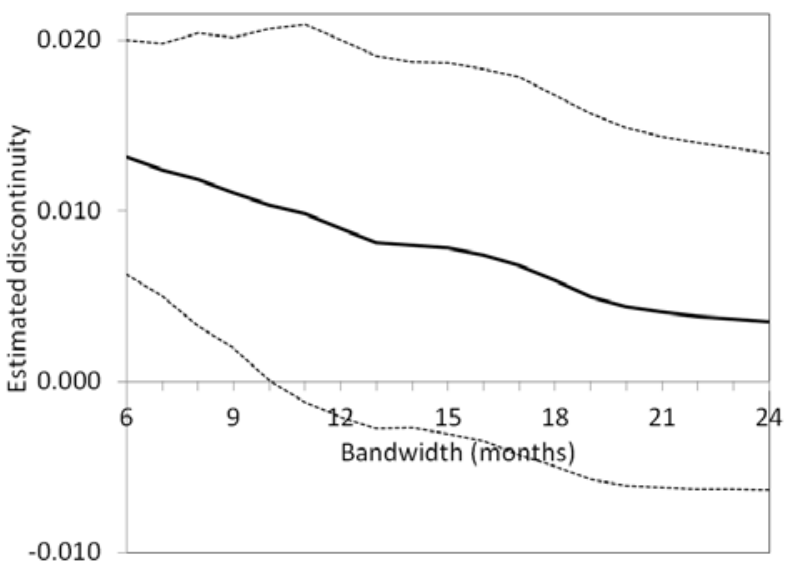

F: Females - Global quadratic

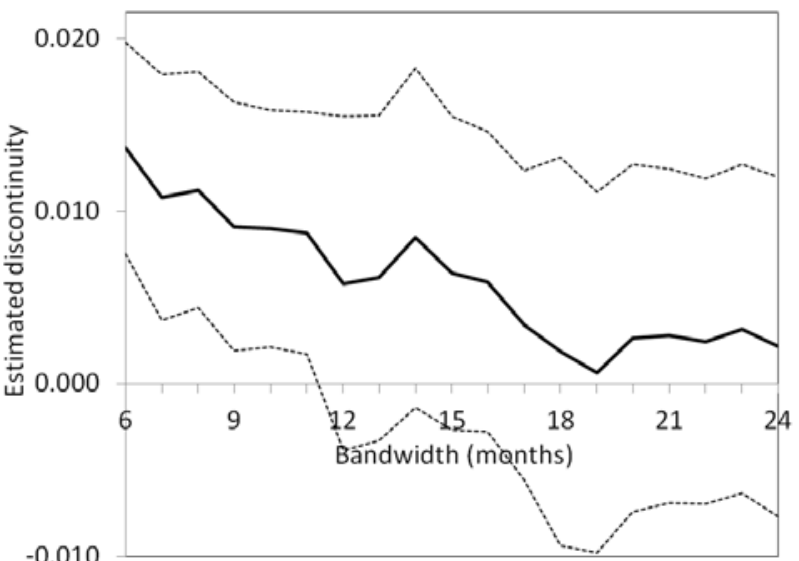

Notes: The figures show the coefficient estimates and 95 percent confidence intervals at different bandwidths between six months and two years. Data is from restricted-use versions of the Multiple Cause of Death data held at the National Center for Health Statistics, including the 1921 to 1948 cohorts. The local linear regressions are estimated using the "robust data-driven" procedures of Calonico, Cattaneo and Titiunik (2014a; 2014b). We use a triangular kernel, robust standard errors, and their bias correction procedures. The global parametric regressions allow for the polynomial to vary either side of the discontinuity and we report robust standard errors. The estimates are stable and statistically significant for the full sample and for males, but not for females. 
Appendix Figure A3. The Distribution of Placebo Female Mortality Estimates for +/-60 Months of Age 62 Compared to the Estimate at Age 62 (Diamond, labeled)

\section{A: Local linear specification}

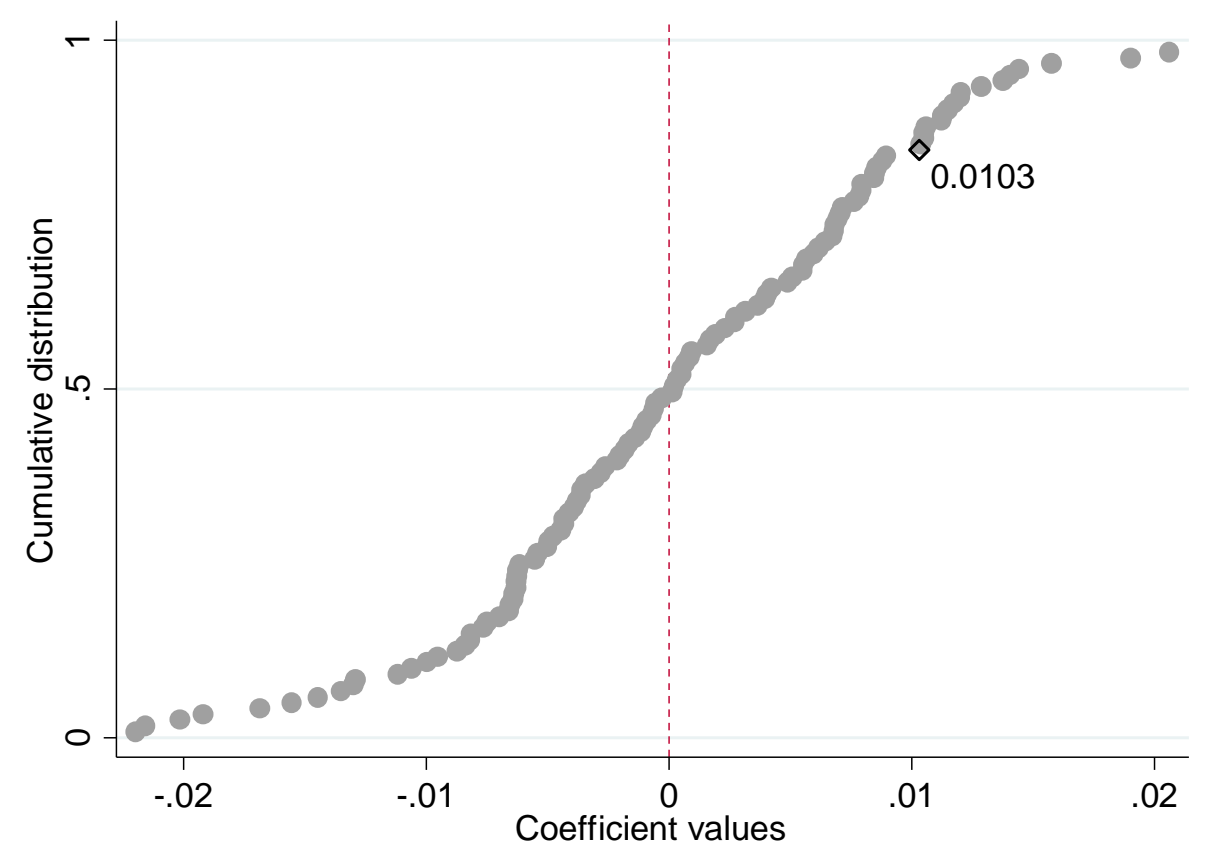

B: Global quadratic specification

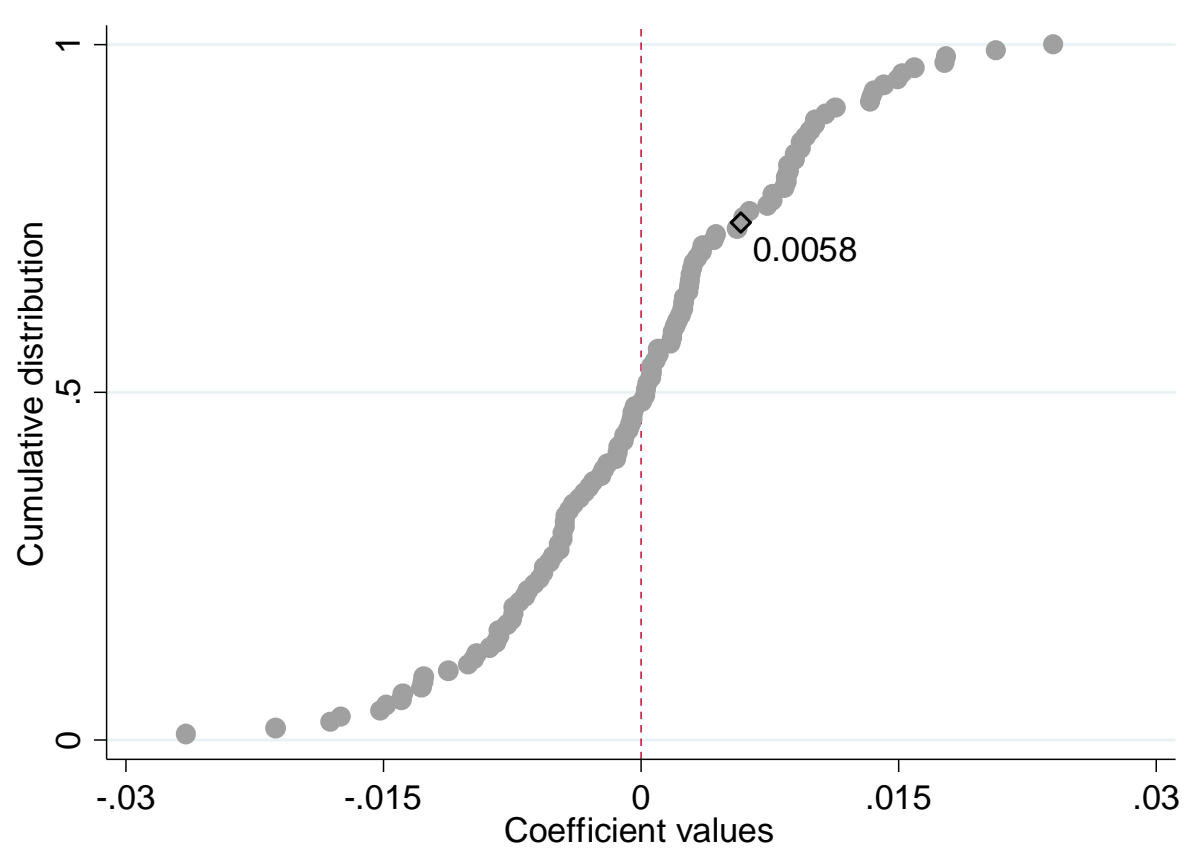

Notes: Data is from restricted-use versions of the Multiple Cause of Death data held at the National Center for Health Statistics including the 1921 to 1948 cohorts. The figures show the conditional density functions of point estimates using each month +/- 60 months before and after age 62 as placebos. The red diamond represents the regression discontinuity estimate at age 62; the values of these estimates are shown in the figures. 


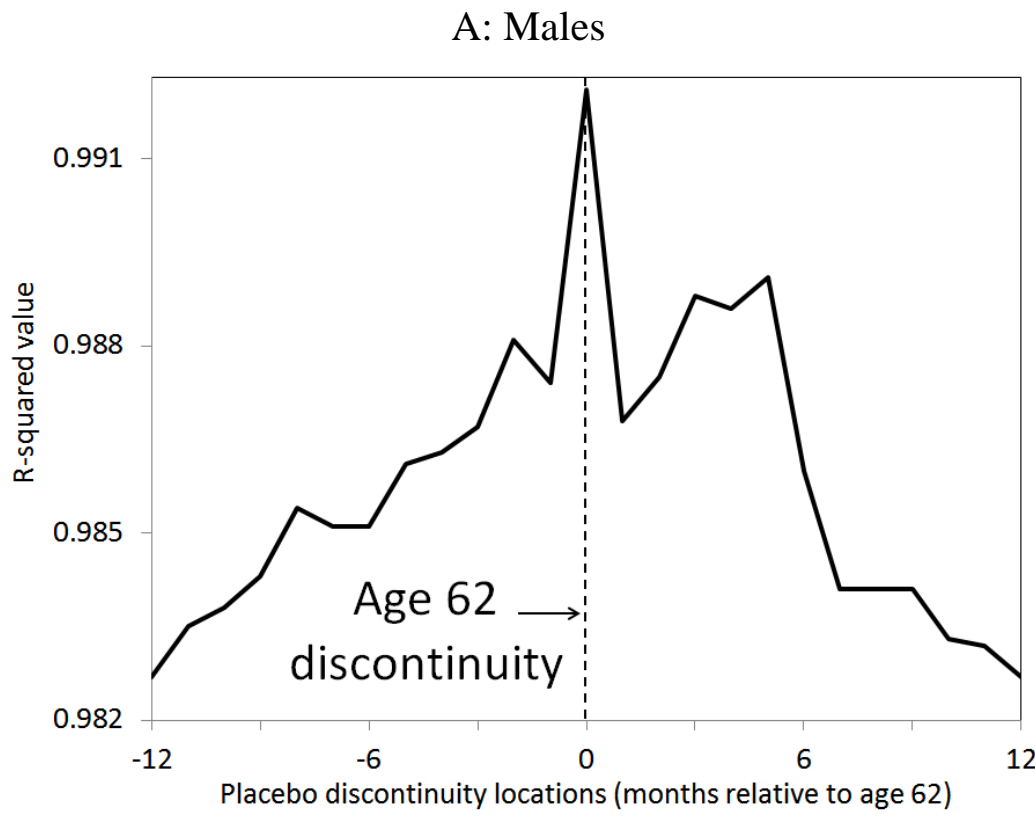

B: Females

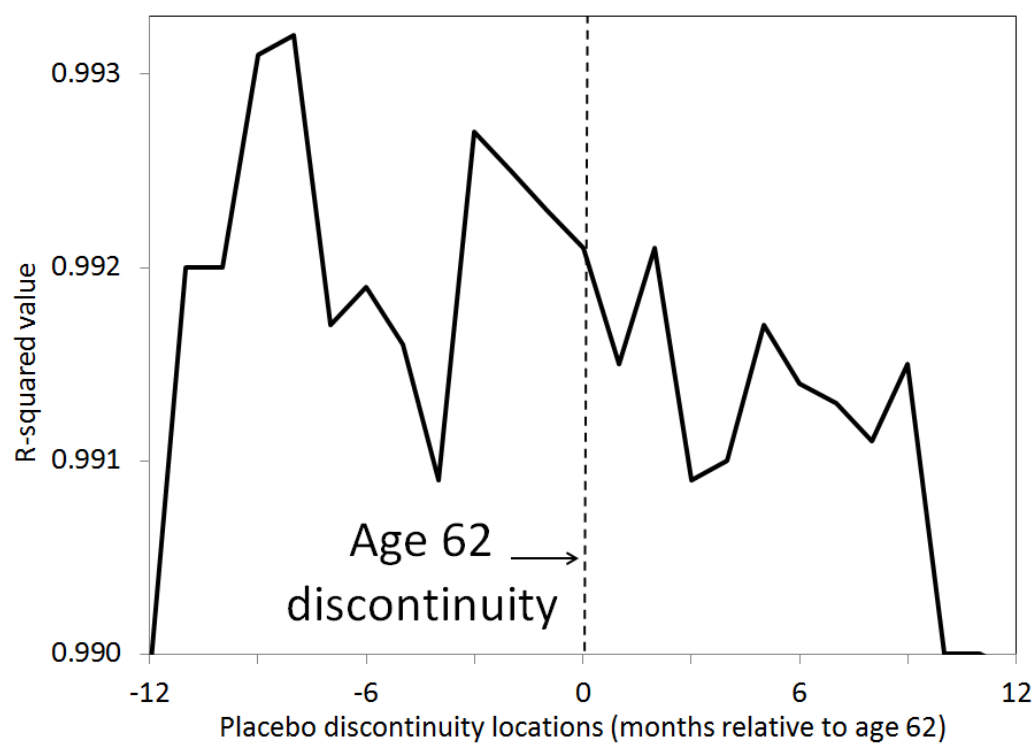

Notes: We compare R-squared when the discontinuity is at age 62 to when it is placed at other locations in a 24month window around age 62. We use the global quadratic specification and data from restricted-use versions of the Multiple Cause of Death data held at the National Center for Health Statistics, which include deaths for the 1921 to 1948 cohorts. The figures show the R-squared statistics as a measure of model fit when the discontinuity is at each age, in months. The dashed line shows the regression discontinuity estimate at age 62 . 


\section{A: All}

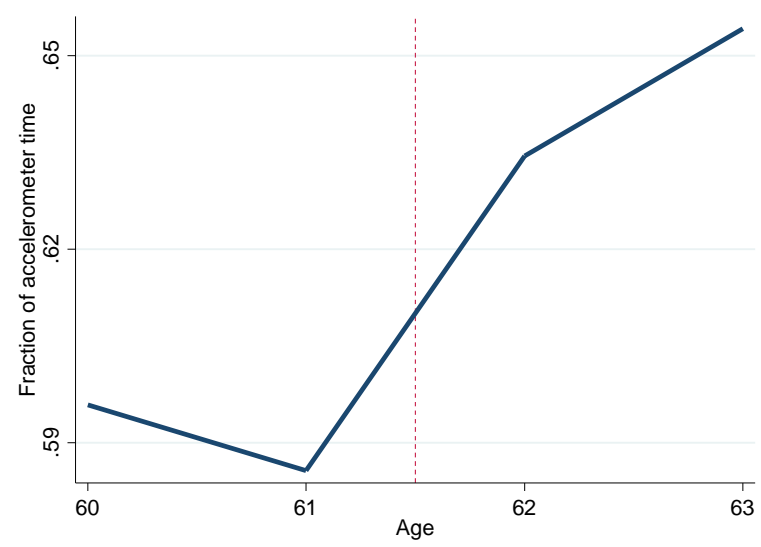

C: Males

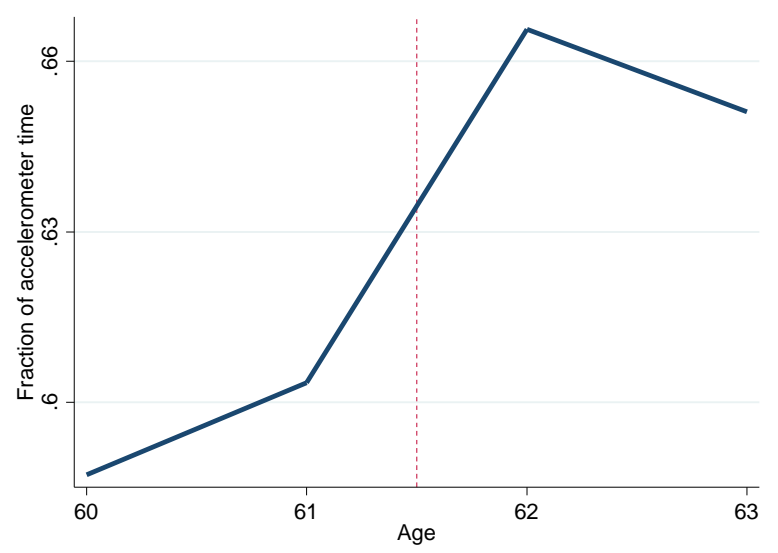

E: Females

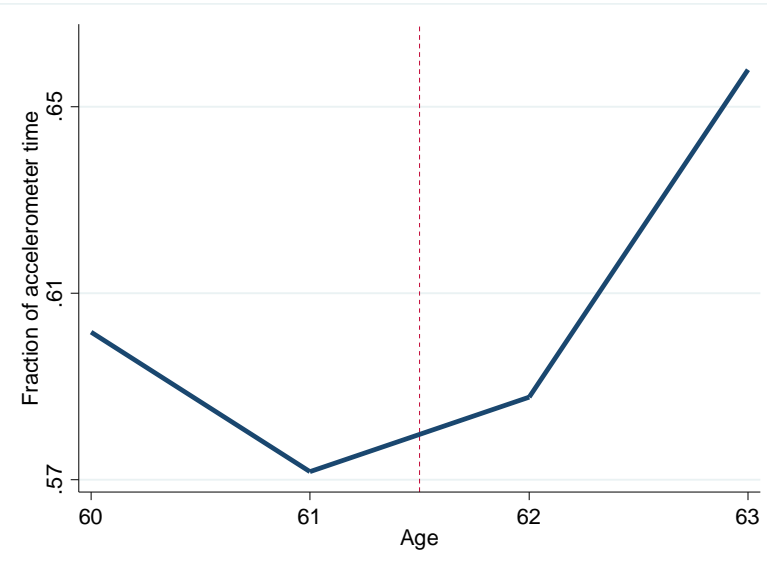

B: All, weekdays 8am-6pm vs. other times

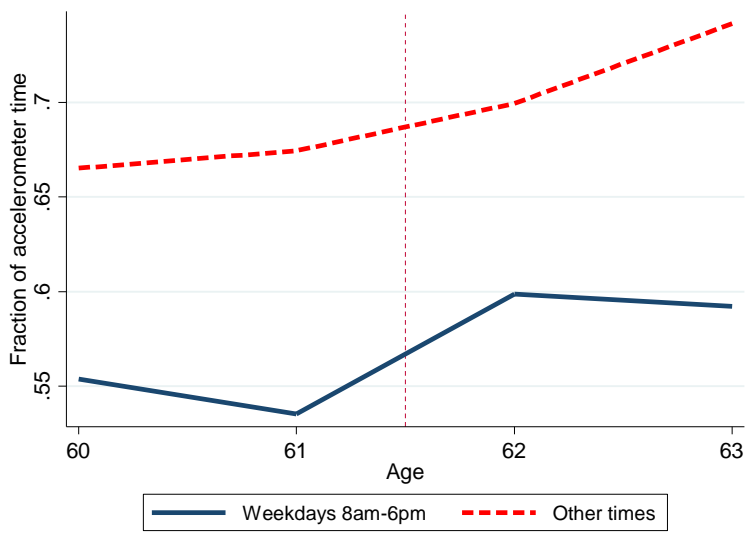

D: Males, weekdays 8am-6pm vs. other times

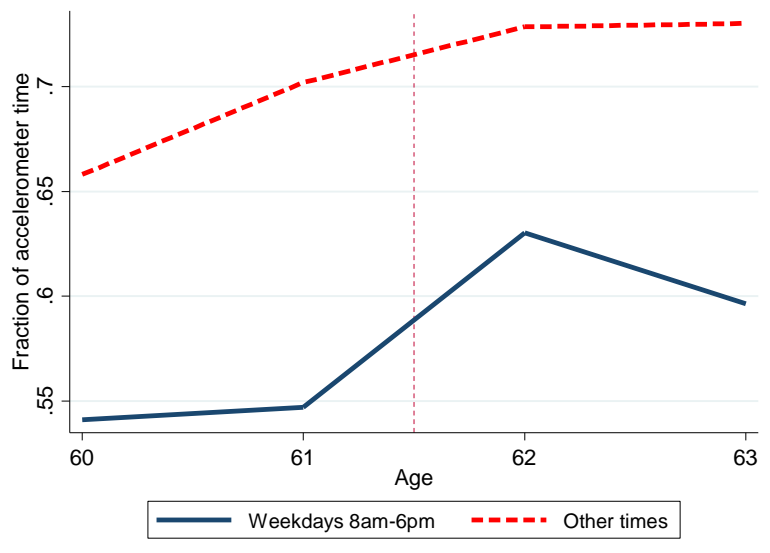

F: Females, weekdays 8am-6pm vs. other times

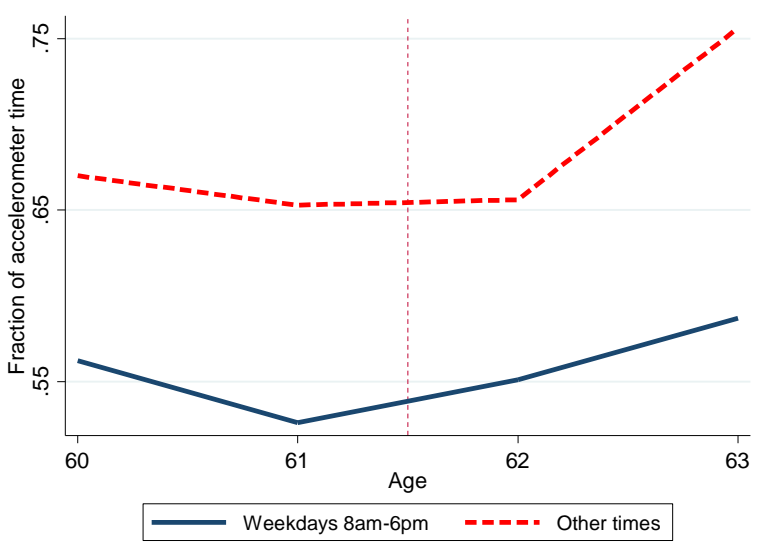

Notes: These figures are based on Actigraph accelerometer data collected from National Health and Nutritional Examination Survey (NHANES) 2003/04 and 2005/06 participants. Sedentary is defined as less than 100 counts per minute and outcome measured is the fraction of sedentary time when the accelerometer was worn. Participants are included if they were aged 60 to 63 and wore their accelerometer between 8am and 6pm Monday and Friday. The sample consists of 92 males and 87 females. 
Appendix Table A1. Full Set of Coefficients from Global Quadratic Regression

\begin{tabular}{|c|c|c|c|}
\hline Regression type & $\begin{array}{l}\text { All } \\
\text { (1) }\end{array}$ & $\begin{array}{l}\text { Males } \\
\text { (2) }\end{array}$ & $\begin{array}{c}\text { Females } \\
\text { (3) }\end{array}$ \\
\hline Post62 [Primary coefficient of interest] & $\begin{array}{c}0.0135 * * * \\
(0.0043)\end{array}$ & $\begin{array}{c}0.0185 * * * \\
(0.0049)\end{array}$ & $\begin{array}{c}0.0058 \\
(0.0049)\end{array}$ \\
\hline AgeDeath & $\begin{array}{c}0.0042 * * * \\
(0.0013)\end{array}$ & $\begin{array}{c}0.0039^{* * *} \\
(0.0012)\end{array}$ & $\begin{array}{c}0.0047^{* *} \\
(0.0019)\end{array}$ \\
\hline AgeDeath $^{2}(\mathrm{x} 100)$ & $\begin{array}{c}-0.0111 \\
(0.0113)\end{array}$ & $\begin{array}{l}-0.0085 \\
(0.0096)\end{array}$ & $\begin{array}{l}-0.0150 \\
(0.0175)\end{array}$ \\
\hline Post62 x AgeDeath & $\begin{array}{c}0.0016 \\
(0.0016)\end{array}$ & $\begin{array}{c}0.0004 \\
(0.0018)\end{array}$ & $\begin{array}{c}0.0035 \\
(0.0021)\end{array}$ \\
\hline Post62 x AgeDeath ${ }^{2}(\mathrm{x} 100)$ & $\begin{array}{c}0.0068 \\
(0.0130)\end{array}$ & $\begin{array}{c}0.0126 \\
(0.0142)\end{array}$ & $\begin{array}{c}-0.0021 \\
(0.0188)\end{array}$ \\
\hline Constant & $\begin{array}{c}11.120^{* * *} \\
(0.003)\end{array}$ & $\begin{array}{c}10.612^{* * *} \\
(0.003)\end{array}$ & $\begin{array}{c}10.199 * * * \\
(0.004)\end{array}$ \\
\hline R-squared & 0.995 & 0.992 & 0.992 \\
\hline Number of observations & 24 & 24 & 24 \\
\hline
\end{tabular}

Notes: $* *$ denotes $\mathrm{p}<0.05$, $* * *$ denotes $\mathrm{p}<0.01$. Data is from restricted-use versions of the Multiple Cause of Death data held at the National Center for Health Statistics. The regressions allow for the polynomial to vary either side of the discontinuity and we report robust standard errors. Mortality is measured at the monthly level. See Table 2 and the text for more details. 
Appendix Table A2. Robustness of Regression Estimates

\begin{tabular}{|c|c|c|c|c|c|c|}
\hline & $\begin{array}{c}\text { Main } \\
\text { estimate } \\
(1)\end{array}$ & $\begin{array}{l}\text { Year-of-birth } \\
\text { fixed effects } \\
\text { (2) }\end{array}$ & $\begin{array}{l}\text { Month-of-death } \\
\text { fixed effects } \\
\text { (3) }\end{array}$ & $\begin{array}{l}\text { Using daily } \\
\text { Counts } \\
\text { (4) }\end{array}$ & $\begin{array}{l}\text { Using weekly } \\
\text { counts } \\
\text { (5) }\end{array}$ & $\begin{array}{c}\text { Using SS } \\
\text { eligibility dates } \\
\text { (6) }\end{array}$ \\
\hline & \multicolumn{6}{|c|}{ A: Full sample } \\
\hline Global quadratic & $\begin{array}{c}0.0135 * * * \\
(0.0043)\end{array}$ & $\begin{array}{c}0.0132 * * * \\
(0.0039)\end{array}$ & $\begin{array}{c}0.0133 * * * \\
(0.0041)\end{array}$ & $\begin{array}{c}0.0132 * * * \\
(0.0049)\end{array}$ & $\begin{array}{c}0.0137 * * \\
(0.0067)\end{array}$ & $\begin{array}{c}0.0134 \\
(0.0084)\end{array}$ \\
\hline Global cubic & $\begin{array}{c}0.0197 * * * \\
(0.0049)\end{array}$ & $\begin{array}{c}0.0195 * * * \\
(0.0043)\end{array}$ & $\begin{array}{c}0.0213 * * * \\
(0.0039)\end{array}$ & $\begin{array}{c}0.0204 * * * \\
(0.0067)\end{array}$ & $\begin{array}{c}0.0200 * * \\
(0.099)\end{array}$ & $\begin{array}{c}0.0254 * * * \\
(0.0068)\end{array}$ \\
\hline Global quartic & $\begin{array}{c}0.0193 * * * \\
(0.0051)\end{array}$ & $\begin{array}{c}0.0187 * * * \\
(0.0043)\end{array}$ & $\begin{array}{c}0.0208 * * * \\
(0.0041)\end{array}$ & $\begin{array}{c}0.0224 * * * \\
(0.0081)\end{array}$ & $\begin{array}{c}0.0235^{* *} \\
(0.0114)\end{array}$ & $\begin{array}{c}0.0333 * * * \\
(0.0065)\end{array}$ \\
\hline Local linear & $\begin{array}{c}0.0142 * * * \\
(0.0036)\end{array}$ & -- & -- & $\begin{array}{c}0.0135 * * * \\
(0.0047)\end{array}$ & $\begin{array}{c}0.0223 * * \\
(0.0105)\end{array}$ & $\begin{array}{l}0.0166^{* *} \\
(0.0074)\end{array}$ \\
\hline Bandwidth & 10 months & & & 305 days & 18 weeks & 8 months \\
\hline Local quadratic & $\begin{array}{c}0.0194 * * * \\
(0.0039)\end{array}$ & -- & -- & $\begin{array}{c}0.0221 * * * \\
(0.0077)\end{array}$ & $\begin{array}{c}0.0239 * * \\
(0.0115)\end{array}$ & $\begin{array}{c}0.0359 * * * \\
(0.0043)\end{array}$ \\
\hline \multirow[t]{2}{*}{ Bandwidth } & 7 months & & & 218 days & 27 weeks & 6 months \\
\hline & \multicolumn{6}{|c|}{ B: Males } \\
\hline Global quadratic & $\begin{array}{c}0.0185 * * * \\
(0.0049)\end{array}$ & $\begin{array}{c}0.0176 * * * \\
(0.0043)\end{array}$ & $\begin{array}{c}0.0187 * * * \\
(0.0045)\end{array}$ & $\begin{array}{c}0.0167 * * * \\
(0.0058)\end{array}$ & $\begin{array}{l}0.0173 * \\
(0.0090)\end{array}$ & $\begin{array}{c}0.0227 * * \\
(0.0092)\end{array}$ \\
\hline Global cubic & $\begin{array}{c}0.0236 * * * \\
(0.0060)\end{array}$ & $\begin{array}{c}0.0220 * * * \\
(0.0051)\end{array}$ & $\begin{array}{c}0.0251 * * * \\
(0.0048)\end{array}$ & $\begin{array}{c}0.0252 * * * \\
(0.0076)\end{array}$ & $\begin{array}{l}0.0243 * \\
(0.0129)\end{array}$ & $\begin{array}{c}0.0348 * * * \\
(0.0084)\end{array}$ \\
\hline Global quartic & $\begin{array}{c}0.0243 * * * \\
(0.0082)\end{array}$ & $\begin{array}{c}0.0222 * * * \\
(0.0066)\end{array}$ & $\begin{array}{c}0.0250 * * * \\
(0.0065)\end{array}$ & $\begin{array}{c}0.0265 * * * \\
(0.0092)\end{array}$ & $\begin{array}{l}0.0286^{*} \\
(0.0154)\end{array}$ & $\begin{array}{c}0.0459 * * * \\
(0.0078)\end{array}$ \\
\hline Local linear & $\begin{array}{c}0.0215^{* * *} \\
(0.0041)\end{array}$ & -- & -- & $\begin{array}{c}0.0135 * * * \\
(0.0047)\end{array}$ & $\begin{array}{l}0.0162^{*} \\
(0.0084)\end{array}$ & $\begin{array}{c}0.0250 * * * \\
(0.0085)\end{array}$ \\
\hline Bandwidth & 7 months & & & 225 days & 46 weeks & 9 months \\
\hline Local quadratic & $\begin{array}{c}0.0233 * * * \\
(0.0058)\end{array}$ & -- & -- & $\begin{array}{c}0.0221 * * * \\
(0.0077)\end{array}$ & $\begin{array}{l}0.0263^{*} \\
(0.0143)\end{array}$ & $\begin{array}{c}0.0472 * * * \\
(0.0051)\end{array}$ \\
\hline \multirow[t]{2}{*}{ Bandwidth } & 7 months & & & 218 days & 36 weeks & 6 months \\
\hline & \multicolumn{6}{|c|}{ C: Females } \\
\hline Global quadratic & $\begin{array}{c}0.0058 \\
(0.0049)\end{array}$ & $\begin{array}{c}0.0065 \\
(0.0045)\end{array}$ & $\begin{array}{c}0.0049 \\
(0.0050)\end{array}$ & $\begin{array}{c}0.0071 \\
(0.0078)\end{array}$ & $\begin{array}{c}0.0074 \\
(0.0072)\end{array}$ & $\begin{array}{l}-0.0007 \\
(0.0080)\end{array}$ \\
\hline Global cubic & $\begin{array}{c}0.0138 * * * \\
(0.0047)\end{array}$ & $\begin{array}{c}0.0151 * * * \\
(0.0042)\end{array}$ & $\begin{array}{c}0.0153 * * * \\
(0.0038)\end{array}$ & $\begin{array}{c}0.0172 \\
(0.0107)\end{array}$ & $\begin{array}{l}0.0166^{*} \\
(0.0095)\end{array}$ & $\begin{array}{l}0.0111^{*} \\
(0.0058)\end{array}$ \\
\hline Global quartic & $\begin{array}{c}0.0116 * * * \\
(0.0043)\end{array}$ & $\begin{array}{c}0.0127 * * * \\
(0.0036)\end{array}$ & $\begin{array}{c}0.0138 * * * \\
(0.0036)\end{array}$ & $\begin{array}{c}0.0222 \\
(0.0137)\end{array}$ & $\begin{array}{c}0.0222 * * \\
(0.0109)\end{array}$ & $\begin{array}{l}0.0140^{*} \\
(0.0079)\end{array}$ \\
\hline Local linear & $\begin{array}{c}0.0103 * * * \\
(0.0030)\end{array}$ & -- & -- & $\begin{array}{c}0.0104 \\
(0.0083)\end{array}$ & $\begin{array}{c}0.0123 \\
(0.0078)\end{array}$ & $\begin{array}{c}0.0246 * * * \\
(0.0064)\end{array}$ \\
\hline Bandwidth & 6 months & & & 257 days & 30 weeks & 9 months \\
\hline Local quadratic & $\begin{array}{c}0.0131 * * * \\
(0.0026)\end{array}$ & -- & -- & $\begin{array}{c}0.0195 \\
(0.0120)\end{array}$ & $\begin{array}{l}0.0194 * \\
(0.0102)\end{array}$ & $\begin{array}{c}0.0141 * * * \\
(0.0052)\end{array}$ \\
\hline Bandwidth & 8 months & & & 245 days & 33 weeks & 7 months \\
\hline
\end{tabular}

Notes: $*$ denotes $\mathrm{p}<0.10,{ }^{* *}$ denotes $\mathrm{p}<0.05, * * *$ denotes $\mathrm{p}<0.01$. The global parametric regressions use a bandwidth of 12 months or equivalent (i.e., 52 weeks, 365 days) and polynomials that vary on either side of the discontinuity. We allow for an arbitrary correlation in errors by age of death. The nonparametric regressions are estimated using the "robust datadriven” procedures of Calonico, Cattaneo and Titiunik (2014a; 2014b). We use a triangular kernel, robust standard errors, and their bandwidth selection and bias correction procedures. See Table 2 and the text for more details. 
Appendix Table A3. Male Estimates with Additional Controls for Mortality Near Age 62

\begin{tabular}{|c|c|c|c|c|c|c|c|c|c|}
\hline \multirow[t]{2}{*}{ Regression type } & \multicolumn{3}{|c|}{ Quadratic specification } & \multicolumn{3}{|c|}{ Cubic specification } & \multicolumn{3}{|c|}{ Q Quartic specification } \\
\hline & (1) & (2) & (3) & (4) & (5) & (6) & (7) & (8) & (9) \\
\hline Mortality change at 62 & $\begin{array}{l}0.0173^{*} \\
(0.0099\end{array}$ & $\begin{array}{c}0.0218 \\
(0.0217)\end{array}$ & $\begin{array}{c}0.0217 \\
(0.0206)\end{array}$ & $\begin{array}{l}0.0243^{*} \\
(0.0129)\end{array}$ & $\begin{array}{c}0.0329 \\
(0.0449)\end{array}$ & & $\begin{array}{l}0286 * \\
0154)\end{array}$ & $\begin{array}{c}0.0308 \\
(0.0558)\end{array}$ & $\begin{array}{c}0.0301 \\
(0.0539)\end{array}$ \\
\hline \multicolumn{10}{|c|}{ Dummy variables for before 62} \\
\hline \multicolumn{2}{|l|}{ One week before 62} & $\begin{array}{c}0.0067 \\
(0.0164)\end{array}$ & $\begin{array}{c}0.0093 \\
(0.0154)\end{array}$ & & $\begin{array}{c}0.0225 \\
(0.0375)\end{array}$ & $\begin{array}{c}0.0292 \\
(0.036)\end{array}$ & & $\begin{array}{c}0.0207 \\
(0.0474)\end{array}$ & $\begin{array}{r}0.0269 \\
(0.0454)\end{array}$ \\
\hline \multicolumn{2}{|l|}{ Prior 4 weeks before 62} & $\begin{array}{c}-0.0083 \\
(0.015)\end{array}$ & $\begin{array}{l}-0.0060 \\
(0.0140)\end{array}$ & & $\begin{array}{c}0.0031 \\
(0.0278)\end{array}$ & $\begin{array}{c}0.0084 \\
(0.0264)\end{array}$ & & $\begin{array}{c}0.0023 \\
(0.0318)\end{array}$ & $\begin{array}{l}0.0073 \\
(0.03)\end{array}$ \\
\hline \multicolumn{2}{|l|}{ Prior 8 weeks before 62} & $\begin{array}{l}-0.0016 \\
(0.0097)\end{array}$ & $\begin{array}{c}-0.0018 \\
(0.0095)\end{array}$ & & $\begin{array}{c}0.0025 \\
(0.0131)\end{array}$ & $\begin{array}{c}0.0034 \\
(0.0128)\end{array}$ & & $\begin{array}{c}0.0027 \\
(0.0127)\end{array}$ & $\begin{array}{r}0.0036 \\
(0.0122)\end{array}$ \\
\hline \multicolumn{10}{|c|}{ Dummy variables for after 62} \\
\hline One week after 62 & & $\begin{array}{c}0.0186 \\
(0.0132)\end{array}$ & $\begin{array}{l}0.0205^{*} \\
(0.0126)\end{array}$ & & $\begin{array}{c}0.0240 \\
(0.0202)\end{array}$ & $\begin{array}{c}0.0255 \\
(0.0202)\end{array}$ & & $\begin{array}{c}0.0240 \\
(0.0214)\end{array}$ & $\begin{array}{c}0.0297 \\
(0.0214)\end{array}$ \\
\hline Next 4 weeks after 62 & & $\begin{array}{c}-0.0109 \\
(0.0120)\end{array}$ & $\begin{array}{l}-0.0132 \\
(0.0111)\end{array}$ & & $\begin{array}{c}-0.007 \\
(0.0165)\end{array}$ & $\begin{array}{c}-0.0096 \\
(0.016)\end{array}$ & & $\begin{array}{c}-0.0070 \\
(0.0166)\end{array}$ & $\begin{array}{r}-0.0076 \\
(0.0161)\end{array}$ \\
\hline Next 8 weeks after 62 & & $\begin{array}{c}-0.0082 \\
(0.0085)\end{array}$ & $\begin{array}{l}-0.0070 \\
(0.0080)\end{array}$ & & $\begin{array}{c}-0.0068 \\
(0.0097)\end{array}$ & $\begin{array}{l}-0.0057 \\
(0.0093)\end{array}$ & & $\begin{array}{c}-0.0068 \\
(0.0099)\end{array}$ & $\begin{array}{r}-0.0062 \\
(0.0093)\end{array}$ \\
\hline \multicolumn{10}{|l|}{ Fixed effects } \\
\hline Year & No & No & Yes & No & No & Yes & No & No & Yes \\
\hline Month-of-death FE & No & No & Yes & No & No & Yes & No & No & Yes \\
\hline
\end{tabular}

Notes: ** denotes $\mathrm{p}<0.10$, ** denotes $\mathrm{p}<0.05$, *** denotes $\mathrm{p}<0.01$. Data is from restricted-use versions of the Multiple Cause of Death data held at the National Center for Health Statistics. The global parametric regressions allow for the polynomial to vary either side of the discontinuity and we report robust standard errors. The nonparametric regressions are estimated using the "robust data-driven" procedures of Calonico, Cattaneo and Titiunik (2014a; 2014b). We use a triangular kernel, robust standard errors, and their bandwidth selection and bias correction procedures. See text for more details. 
Appendix Table A4. Sensitivity of Male Mortality Estimates at Age 62 to Omitting Census Regions

\begin{tabular}{ccccc}
\hline \hline & $\begin{array}{c}\text { Northeast re- } \\
\text { gion } \\
\text { excluded }\end{array}$ & $\begin{array}{c}\text { Midwest } \\
\text { region } \\
\text { excluded }\end{array}$ & $\begin{array}{c}\text { South re- } \\
\text { gion } \\
\text { excluded }\end{array}$ & $\begin{array}{c}\text { West } \\
\text { region } \\
\text { excluded }\end{array}$ \\
& $(1)$ & $(2)$ & $(3)$ & $(4)$ \\
\hline
\end{tabular}

$\begin{array}{lcccc}\text { Global parametric regressions (bandwidth }=12 \text { months) } & & & \\ \text { Quadratic regression } & 0.0183^{* * *} & 0.0236^{* * *} & 0.0190^{* * *} & 0.0160^{* *} \\ & (0.0036) & (0.0055) & (0.0048) & (0.0065) \\ \text { Cubic regression } & 0.0194^{* * *} & 0.0298^{* * *} & 0.0175^{* * *} & 0.0196^{* *} \\ & (0.0047) & (0.0071) & (0.0059) & (0.0086) \\ \text { Quartic regression } & 0.0230^{* * *} & 0.0304^{* * *} & 0.0183^{* * *} & 0.0205^{* *} \\ & (0.0065) & (0.0086) & (0.0089) & (0.0103)\end{array}$

Local nonparametric regressions

Local linear

$\begin{array}{llll}0.0193^{* * *} & 0.0275^{* * *} & 0.0184^{* * *} & 0.0177^{* * *}\end{array}$

Data-driven bandwidth $\quad 6$ months $\quad 7$ months 8 months 6 months
Local quadratic
$0.0210^{* * *}$
$0.0282 * * *$
$0.0186^{* *}$
$0.0200 * * *$
(0.0046)
(0.0061)
(0.0041)
(0.0077)
Data-driven bandwidth
7 months
7 months
10 months
8 months

Notes: ** denotes $\mathrm{p}<0.05$, *** denotes $\mathrm{p}<0.01$. Data is from restricted-use versions of the Multiple Cause of Death data held at the National Center for Health Statistics. The global parametric regressions allow for the polynomial to vary either side of the discontinuity and we report robust standard errors. The nonparametric regressions are estimated using the "robust data-driven" procedures of Calonico, Cattaneo and Titiunik (2014a; 2014b). We use a triangular kernel, robust standard errors, and their bandwidth selection and bias correction procedures. See text for more details. 
Appendix Table A5. Estimates for Different Cohorts of Males Based on Differences in Full Retirement Age

\begin{tabular}{|c|c|c|}
\hline & $\begin{array}{c}\text { Local } \\
\text { Linear } \\
(1)\end{array}$ & $\begin{array}{c}\text { Global } \\
\text { quadratic } \\
(2)\end{array}$ \\
\hline Cohorts with a FRA equal to 65 years: 1921-1937 & $\begin{array}{c}0.0148 \\
(0.0090) \\
11 \text { months }\end{array}$ & $\begin{array}{c}0.0170 * * \\
(0.0068) \\
12 \text { months }\end{array}$ \\
\hline Cohorts with a FRA greater than 65 years: 1938-1948 & $\begin{array}{c}0.0244^{* *} \\
(0.0099) \\
8 \text { months }\end{array}$ & $\begin{array}{c}0.0179 * * * \\
(0.0069) \\
12 \text { months }\end{array}$ \\
\hline - Cohorts with a FRA between 65 \& 66 years: 1938-1942 & $\begin{array}{c}0.0259 \\
(0.0178) \\
10 \text { months }\end{array}$ & $\begin{array}{c}0.0190 \\
(0.0151) \\
12 \text { months }\end{array}$ \\
\hline - Cohorts with a FRA equal to 66 years: $1943-1948$ & $\begin{array}{c}0.0232 * * \\
(0.0098) \\
7 \text { months }\end{array}$ & $\begin{array}{c}0.0170 * * * \\
(0.0062) \\
12 \text { months }\end{array}$ \\
\hline
\end{tabular}

Notes: ** denotes $\mathrm{p}<0.05, * * *$ denotes $\mathrm{p}<0.01$. FRA is "Full Retirement Age.” For each subgroup, we show the coefficient, standard error and bandwidth used for both the local linear regression (with CCT bandwidth) and global quadratic regression (with 12-month bandwidth). See the notes to Table 2 for more details. 
Appendix Table A6. Assessing the Relationship between the Changes in Mortality and Other Outcomes at Age 62 using the 14 Demographic Subgroups

\begin{tabular}{|c|c|c|}
\hline Regressor used & $\begin{array}{l}\text { Coefficient (s.e.) } \\
\text { from weighted re- } \\
\text { gression } \\
(1)\end{array}$ & $\begin{array}{l}\text { Coefficient (s.e.) } \\
\text { from unweighted } \\
\text { regression } \\
(2)\end{array}$ \\
\hline \multicolumn{3}{|l|}{ Social Security outcomes } \\
\hline (a) Fraction who began claiming Social Security & $\begin{array}{l}-0.007 \\
(0.491)\end{array}$ & $\begin{array}{c}0.195 \\
(0.449)\end{array}$ \\
\hline $\begin{array}{l}\text { (b) Fraction who began claiming Social Security } \\
\text { (change in means, ages 62-61) }\end{array}$ & $\begin{array}{c}0.070 \\
(0.130)\end{array}$ & $\begin{array}{l}-0.041 \\
(0.169)\end{array}$ \\
\hline (c) Fraction receiving Social Security payments & $\begin{array}{l}-0.049 \\
(0.039)\end{array}$ & $\begin{array}{c}0.050 \\
(0.056)\end{array}$ \\
\hline \multicolumn{3}{|l|}{ Labor force participation outcomes } \\
\hline (d) Fraction retired & $\begin{array}{c}0.073^{* * *} \\
(0.021)\end{array}$ & $\begin{array}{l}0.074^{* *} \\
(0.029)\end{array}$ \\
\hline (e) Fraction in labor force & $\begin{array}{c}-0.060 * * * \\
(0.019)\end{array}$ & $\begin{array}{c}-0.074 * * * \\
(0.019)\end{array}$ \\
\hline (f) Fraction working for pay & $\begin{array}{l}-0.070 * * \\
(0.026)\end{array}$ & $\begin{array}{c}-0.097 * * * \\
(0.025)\end{array}$ \\
\hline \multicolumn{3}{|l|}{ Health insurance outcomes } \\
\hline (g) Fraction with health insurance & $\begin{array}{l}-0.034 \\
(0.071)\end{array}$ & $\begin{array}{c}0.013 \\
(0.067)\end{array}$ \\
\hline (h) Average number of health insurance plans & $\begin{array}{l}-0.013 \\
(0.021)\end{array}$ & $\begin{array}{l}-0.004 \\
(0.020)\end{array}$ \\
\hline \multicolumn{3}{|l|}{ Household income (change in means) } \\
\hline (i) Average annual change between 61 and 63 & $\begin{array}{c}0.046 \\
(0.046)\end{array}$ & $\begin{array}{c}0.007 \\
(0.046)\end{array}$ \\
\hline $\begin{array}{l}\text { (j) Average annual change between } 61 \text { and 63, Jan.-Mar. } \\
\text { sample }\end{array}$ & $\begin{array}{c}0.047 \\
(0.048)\end{array}$ & $\begin{array}{c}0.001 \\
(0.008)\end{array}$ \\
\hline
\end{tabular}

Notes: ** denotes $\mathrm{p}<0.05, * * *$ denotes $\mathrm{p}<0.01$. The coefficients and standard errors come from regressions with the mortality coefficients as the dependent variable and the particular outcome as the independent variable. The results in column (1) come from regressions weighted by the number of deaths in each group. 
Appendix Table A7. Estimated Change in Mortality at Age 62 among Males, By Cause of Death

\begin{tabular}{|c|c|c|c|c|c|c|c|}
\hline & $\begin{array}{c}\text { Local } \\
\text { linear } \\
(1) \\
\end{array}$ & $\begin{array}{c}\text { Global } \\
\text { quadratic } \\
(2)\end{array}$ & $\begin{array}{c}\text { Fraction } \\
\text { of deaths } \\
(3)\end{array}$ & & $\begin{array}{c}\text { Local } \\
\text { linear } \\
(4) \\
\end{array}$ & $\begin{array}{cc}\text { Global } & F \\
\text { quadratic } & \\
(5) & \end{array}$ & $\begin{array}{c}\text { Fraction } \\
\text { deaths } \\
(6)\end{array}$ \\
\hline $\begin{array}{l}\text { Cardiovascular and } \\
\text { respiratory conditions }\end{array}$ & $\begin{array}{l}0.0250 * * \\
(0.0106)\end{array}$ & $\begin{array}{c}0.0135 \\
(0.0119)\end{array}$ & $39.2 \%$ & Cancers & $\begin{array}{r}0.0262^{* * *} \\
(0.0072)\end{array}$ & $\begin{array}{c}* 0.0263 * * * \\
(0.0084)\end{array}$ & * $33.6 \%$ \\
\hline - Heart attacks & $\begin{array}{c}0.0159 \\
(0.0138)\end{array}$ & $\begin{array}{c}0.0072 \\
(0.0172)\end{array}$ & $19.4 \%$ & $\begin{array}{l}\text { - Single cause } \\
\text { cancer }\end{array}$ & $\begin{array}{c}0.0069 \\
(0.0071)\end{array}$ & $\begin{array}{c}0.0178 \\
(0.0087)\end{array}$ & $12.3 \%$ \\
\hline $\begin{array}{l}\text { - Chronic obstructive } \\
\text { pulmonary disease (COPD) }\end{array}$ & $\begin{array}{c}0.0696 * * * \\
(0.0089)\end{array}$ & $\begin{array}{c}0.0496 * * \\
(0.0180)\end{array}$ & $4.2 \%$ & - Lung cancer & $\begin{array}{r}0.0531^{* * *} \\
(0.0097)\end{array}$ & $\begin{array}{c}* 0.0510 * * * \\
(0.0108)\end{array}$ & * $13.1 \%$ \\
\hline $\begin{array}{l}\text { - Not heart attacks or } \\
\text { COPD }\end{array}$ & $\begin{array}{c}0.0064 \\
(0.0106)\end{array}$ & $\begin{array}{c}0.0118 \\
(0.0115)\end{array}$ & $15.6 \%$ & $\begin{array}{l}\text { - Not lung can- } \\
\text { cer }\end{array}$ & $\begin{array}{c}0.0099 \\
(0.0080)\end{array}$ & $\begin{array}{c}0.0106 \\
(0.0092)\end{array}$ & $20.6 \%$ \\
\hline External causes & $\begin{array}{c}0.0314 * * * \\
(0.0103)\end{array}$ & $\begin{array}{c}0.0399 * * \\
(0.0163)\end{array}$ & $5.0 \%$ & $\begin{array}{l}\text { All other } \\
\text { causes }\end{array}$ & $\begin{array}{c}0.0113 \\
(0.0109)\end{array}$ & $\begin{array}{c}0.0109 \\
(0.0106)\end{array}$ & $22.1 \%$ \\
\hline - Motor vehicle accidents & $\begin{array}{c}0.1421 * * * \\
(0.0376)\end{array}$ & $\begin{array}{c}0.1526 * * * \\
(0.0508)\end{array}$ & $1.3 \%$ & & & & \\
\hline $\begin{array}{l}\text { - Not motor vehicle } \\
\text { accidents }\end{array}$ & $\begin{array}{l}-0.0088 \\
(0.0165)\end{array}$ & $\begin{array}{c}0.0007 \\
(0.0159)\end{array}$ & $3.8 \%$ & & & & \\
\hline
\end{tabular}

Notes: $* *$ denotes $\mathrm{p}<0.05$, *** denotes $\mathrm{p}<0.01$. We show coefficients and standard errors for local linear (using bandwidths selected based on the procedures of Calonico, Cattaneo, Titiunik (2014a; 2014b)) and global quadratic regressions (using a 12-month bandwidth). Fraction of deaths is for male deaths at age 61 and 62. See Table 2 and the text for more details.

Appendix Table A8. The Impact of Changing Employment Levels on Mortality at Age 62

\begin{tabular}{|c|c|c|c|c|c|c|}
\hline & \multicolumn{3}{|c|}{ Males } & \multicolumn{3}{|c|}{ Females } \\
\hline & $\begin{array}{c}\text { Retirement } \\
(1) \\
\end{array}$ & $\begin{array}{c}\text { Labor force } \\
\text { participation } \\
(2) \\
\end{array}$ & $\begin{array}{l}\text { Working } \\
\text { for pay } \\
(3)\end{array}$ & $\begin{array}{c}\text { Retirement } \\
(1) \\
\end{array}$ & $\begin{array}{l}\text { LFP } \\
(2)\end{array}$ & $\begin{array}{c}\text { Working } \\
\text { for pay } \\
(3)\end{array}$ \\
\hline $\begin{array}{l}\text { Percentage change } \\
\text { in mortality (a) }\end{array}$ & $\begin{array}{c}0.019 * * * \\
(0.005)\end{array}$ & $\begin{array}{c}0.019 * * * \\
(0.005)\end{array}$ & $\begin{array}{c}0.019 * * * \\
(0.005)\end{array}$ & $\begin{array}{c}0.006 \\
(0.005)\end{array}$ & $\begin{array}{c}0.006 \\
(0.005)\end{array}$ & $\begin{array}{c}0.006 \\
(0.005)\end{array}$ \\
\hline $\begin{array}{l}\text { Percentage point } \\
\text { change in work (b) }\end{array}$ & $\begin{array}{c}0.110 * * * \\
(0.023)\end{array}$ & $\begin{array}{c}-0.082^{* * *} \\
(0.022)\end{array}$ & $\begin{array}{c}-0.082 * * * \\
(0.022)\end{array}$ & $\begin{array}{c}0.042 \\
(0.030)\end{array}$ & $\begin{array}{l}-0.001 \\
(0.041)\end{array}$ & $\begin{array}{l}-0.008 \\
(0.036)\end{array}$ \\
\hline $\begin{array}{l}\text { Mortality-to-work } \\
\text { ratio }[(\mathrm{a}) /(\mathrm{b})]\end{array}$ & $\begin{array}{c}0.169 * * * \\
(0.057)\end{array}$ & $\begin{array}{c}-0.226 * * * \\
(0.085)\end{array}$ & $\begin{array}{c}-0.225 * * * \\
(0.084)\end{array}$ & $\begin{array}{c}0.138 \\
(0.153)\end{array}$ & $\begin{array}{l}-4.02 \\
(114)\end{array}$ & $\begin{array}{l}-0.719 \\
(3.26)\end{array}$ \\
\hline
\end{tabular}

Notes: ** denotes $\mathrm{p}<0.05$, $* * *$ denotes $\mathrm{p}<0.01$. The first row shows coefficients and standard errors for the estimated change in mortality at age 62 using the global quadratic RD specification. These are from Table 2 . The second row shows the coefficients and standard errors for the percentage point changes in employment outcomes at age 62, which are calculated from the HRS using the global quadratic specification. The third row shows the estimated percentage increase in mortality if it is attributed to one of three measures of work levels: fraction retired, labor force participation, and fraction working for pay. It is calculated as the ratio of the first two rows, with the standard errors calculated using the delta method. 


\section{RECENT WORKING PAPERS FROM THE CENTER FOR RETIREMENT RESEARCH AT BOSTON COLLEGE}

How Would Investing in Equities Have Affected the Social Security Trust Fund?

Gary Burtless, Anqi Chen, Wenliang Hou, Alicia H. Munnell, and Anthony Webb, July 2016

Are Early Claimers Making a Mistake?

Alicia H. Munnell, Geoffrey T. Sanzenbacher, Anthony Webb, and Christopher M. Gillis, July 2016

Marital Histories, Gender, and Financial Security in Late Mid-Life: Evidence from Four Cohorts in the Health and Retirement Study

Amelia Karraker and Cassandra Dorius, July 2016

Pension Participation, Wealth, and Income: 1992-2010

Alicia H. Munnell, Wenliang Hou, Anthony Webb, and Yinji Li, July 2016

The Interconnected Relationships of Health Insurance, Health, and Labor Market Outcomes

Matthew S. Rutledge, July 2016

Labor Force Dynamics in the Great Recession and Its Aftermath: Implications for Older Workers

Gary Burtless, July 2016

Elderly Poverty in the United States in the 21st Century: Exploring the Role of Assets in the Supplemental Poverty Measure

Christopher Wimer and Lucas Manfield, November 2015

The Economic Burden of Out-of-Pocket Medical Expenditures Before and After Implementation of the Medicare Prescription Drug Program

Ayse Akincigil and Karen Zurlo, November 2015

The Impact of Temporary Assistance Programs on the Social Security Claiming Age Geoffrey T. Sanzenbacher, April Yanyuan Wu, and Matthew S. Rutledge, October 2015

Do Households Increase Their Savings When the Kids Leave Home?

Irena Dushi, Alicia H. Munnell, Geoffrey T. Sanzenbacher, and Anthony Webb, September 2015

Evaluating the Impact of Social Security Benefits on Health Outcomes Among the Elderly Padmaja Ayyagari, September 2015

All working papers are available on the Center for Retirement Research website (http://crr.bc.edu) and can be requested by e-mail (crr@bc.edu) or phone (617-552-1762). 